\title{
Review of Nanocellulose for Sustainable Future Materials
}

\author{
Joo-Hyung Kim1, Bong Sup Shim², Heung Soo Kim³, Young-Jun Lee', Seung-Ki Min', \\ Daseul Jang', Zafar Abas $^{3}$, and Jaehwan Kim", \\ Department of Mechanical Engineering, Inha University, 100, Inha-ro, Nam-gu, Incheon, 402-751, South Korea \\ 2 Department of Chemical Engineering, Inha University, 100, Inha-ro, Nam-gu, Incheon, 402-751, South Korea \\ 3 Department of Mechanical, Robotics and Energy Engineering, Dongguk University-Seoul, 30, Pildong-ro 1-gil, Jung-gu, Seoul, 100-715, South Korea \\ \# Corresponding Author / E-mail: jaehwan@inha.ac.kr, TEL: +82-32-860-7326, FAX: +82-32-832-7325
}

KEYWORDS: Nanocellulose, Renewable materials, Composites, Smart materials, Ultrahigh strength fibers

\begin{abstract}
Cellulose, the chain of glucose residues easily obtained from nature, is the most common natural polymer. Owing to its own unique material properties, compared to the conventional usage, nanocellulose (NC) with a crystalline structure can be considered to be used in various industrial applications. As a novel sustainable future material, we review the recent achievements of NC from the view point of material extraction and the composite processes to some extended important applications. While the mechanical properties of NCs and the energy consumption during their composite processing are the key considerations, their application potentials have never been limited to mechanical or commodity products as conventional celluloses. In the latter part of this review, emerging engineering applications of NCs such as energy storage, flexible electronics, and smart materials will be further discussed for readers searching future high-end eco-friendly functional materials. Also some suggestions for potential applications will be also discussed.
\end{abstract}

NOMENCLATURE
$\mathrm{a}=$ directional orientation of the system
$\mathrm{h}=$ strip thickness with strip thickness and strip thickness
strip thickness

\section{Introduction}

As our society is evolved to technology oriented society, environmental issues become more important for the desires of easiness, comfort-ness and safety. Modern technologies - information technology, biotechnology and nanotechnology - have contributed to develop our society in all different fields. However, future technologies should concern more about our living environment and harmonize with it, which is related to sustainability in future technologies.

The materials used in everyday can influence our whole life culture, economy and politics far more deeply than we are inclined to admit: this is, indeed, recognized by the archaeologists when they talk about the 'stone age', the 'bronze age' and the 'iron age'. ${ }^{1}$ Development of new materials is a corner stone of sustainable future technologies. Strong and light structural materials can reduce the weight of automobiles and aircrafts, which can drastically improve agility and reduce energy consumption as well as air pollution. To meet the technological requirement, new materials are under development for stronger and lighter materials. In addition to the technological requirement, economic and social aspects are important for developing new materials. So far petroleum based materials have been extensively developed and used. These materials are competitive from the economic point of view.

Beyond the performance of materials and economic aspects, life cycle assessment is also important for our society. At the end of life cycle of the materials, products should be able to reuse, recycle or disposal. To disposal, the materials used for products should be compostable in a short time. However, most petroleum based materials take too long to be composted. It seems very possible that the coming future materials will resemble natural materials like wood and bone, so called biomimetic science and engineering.

Renewable materials are those which can be manufactured or generated quickly enough to keep pace with how fast they are used up. Renewable materials can be made from natural products or 
synthetically produced, and often include recycled products. Renewable materials are sustainable materials, for example, cellulose, chitosan, starch, collagen, soy protein and casein. These raw materials are abundant and biodegradable, and are used to make diverse products such as adhesives and cardboard. The use of renewable materials is very important for carbon capture and sequestration, which prevents large amount of carbon dioxide from being released into to the atmosphere so as to reduce global warming.

As the most important skeletal component in plants, cellulose is an almost inexhaustible polymeric raw material with fascinating structure and properties. Formed by the repeated connection of d-glucose building blocks, the highly functionalized, linear stiff-chain homopolymer is characterized by its hydrophilicity, chirality, biodegradability, broad chemical modifying capacity, and its formation of versatile semi-crystalline fiber morphologies. ${ }^{2}$ Cellulose is the most common organic polymer, representing about 1.5 trillion tons of the total annual biomass production, and is considered as an almost inexhaustible source of raw material for the increasing demand for environmentally friendly and biocompatible products. The potential of cellulose is tremendous. ${ }^{3}$ There is still plenty to discover and celebrate in cellulose.

Fig. 1 shows a hierarchical structure of cellulose owned from wood. ${ }^{4}$ Cell walls of wood are made with macrofibers of cellulose, hemicellulose and lignin, which form a cellulose fiber composite. The macrofibers are composed of microfibrils, which are formed with nanofibrils of cellulose. Interestingly, nanofibrils of cellulose have crystal part and amorphous part in a row. The crystal part of cellulose cannot be broken due to strong hydrogen bond of hydroxyl groups in cellulose. Rather cellulose crystalline has several polymorphs: cellulose I, II, III, IV. Cellulose I is the crystalline cellulose that is naturally produced by a variety of organisms, which is sometimes referred to as natural cellulose. Its structure is thermodynamically metastable and can be converted to either cellulose II or III. Cellulose II is the most stable crystalline structure and can be produced by regeneration and mercerization. There are two kind of nanocellulose (NC): cellulose nanofiber (CNF) and cellulose nanocrystal (CNC). $\mathrm{NC}-\mathrm{CNC}$ and $\mathrm{CNF}-$ has unique properties including high $\mathrm{E}$, dimensional stability, low thermal expansion coefficient, outstanding reinforcing potential and transparency ${ }^{4,5}$ It is very highly crystalline with a very high $E \sim 150 \mathrm{GPa}$, which can shows very strong mechanical properties. Fig. 2 shows the comparison of specific strength and $\mathrm{E}(E)$ of various materials. ${ }^{4}$

This paper reviews recent advancement of $\mathrm{NC}$ research and discusses about its possibility for sustainable future materials. The second chapter focuses on $\mathrm{NC}$ and its extraction from of natural resources. The extracted NC can be aligned, processed and modified for long fibers, films, powders and suspensions. These materials can be applied for environmentally friendly engineering composites that surpass current technological limits of composite materials. The third chapter covers the engineering composites. The fourth chapter encompasses smart materials and structure applications. Lastly, these materials can be applied to energy devices, for example, paper batteries, supercapacitors and paper displays, which are explained in chapter four. Lastly challenges and opportunities of this research will be shown with summary.

\section{Extraction of NC from Natural Resources}

\subsection{Nanocellulose}

Cellulose can be extracted from wood, plants, bacteria and algae. As shown in Fig. 1, for example, intrinsic ingredient of wood is cellulose microfibrils that have $20-100 \mathrm{~nm}$ cross-sectional size with $100-200 \mathrm{~nm}$ long fiber length. It is commonly recognized that amorphous and crystal parts of cellulose are sequentially located along the fiber direction in a row, meanwhile amorphous parts separate nanofibrils in cross section. It is almost impossible to break the crystal parts of cellulose because of strong hydrogen bonding between hydroxyl groups in cellulose. On the other hand, amorphous parts of cellulose are relatively easy to be broken. Thus, extraction of $\mathrm{NC}$ from natural resources includes pre-treatment of natural resources and breaking of amorphous parts of cellulose so as to extract $\mathrm{NC}$ in $\mathrm{CNC}$ and $\mathrm{CNF}$ forms. $\mathrm{CNC}$ and $\mathrm{CNF}$ are extremely strong comparing with other materials. Table 1 shows the comparison of material properties of cellulose with other materials. ${ }^{4}$

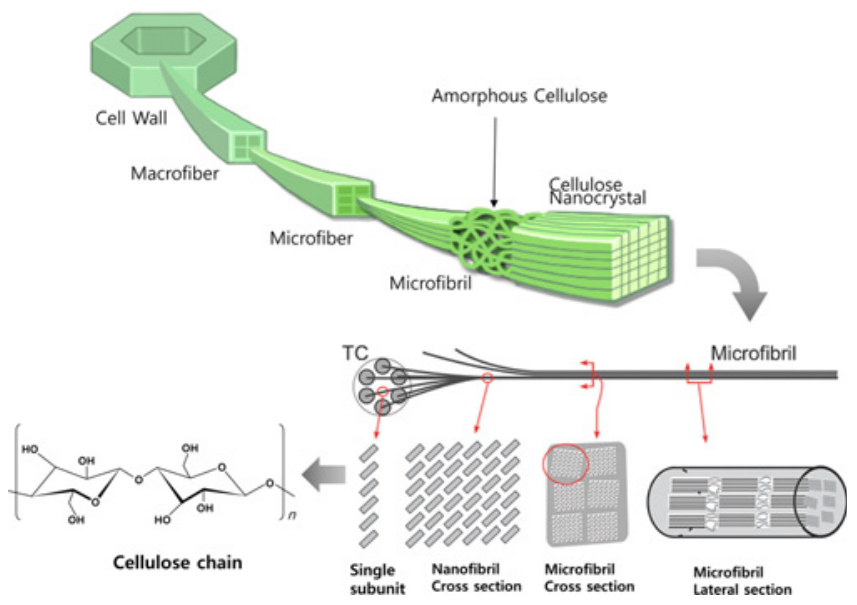

Fig. 1 Hierarchical structure of cellulose (reproduced from Ref. 4 with permission)

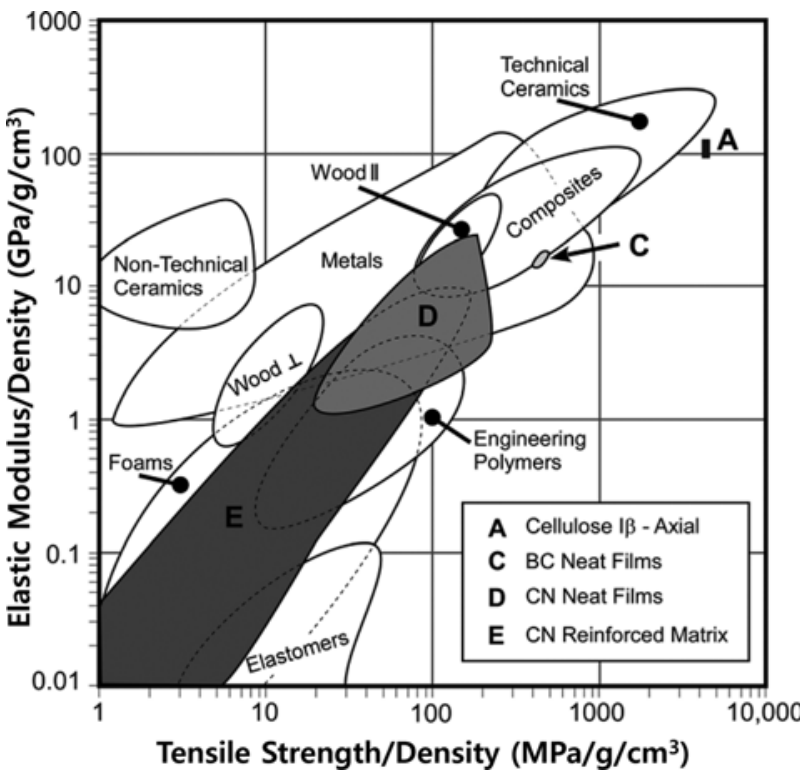

Fig. 2 Comparison of specific strength and Young's modulus of different materials (redrawn from Ref. 4) 
However, extraction of $\mathrm{CNF}$ and $\mathrm{CNC}$ from natural resources is not easy because there are various resources and composition as well as formation of cellulose is different. Not only wood, but also bamboo, crop residues, oil palm empty fruit bunches, sugar cane gagasse, tunicates, and bacterial cellulose are some of cellulose resources. Pulping is well known method for breaking wood fibers by chemical and mechanical methods so as to produce wood microfibers. Here, we are not going to deeply touch pulping because our concern is for extracting cellulose microfibrils and nanofibrils like CNF and CNC. There are two distinctive methods for $\mathrm{CNF}$ and $\mathrm{CNC}$ extraction: mechanical, chemical and physical methods. However, extraction of $\mathrm{CNF}$ and $\mathrm{CNC}$ requires a multi-stage process involving vigorous chemical and/or mechanical operations. ${ }^{6}$ For example, chemical treatment, mechanical refining, homogenization and crushing of the water-soaked pulp in the presence of liquid nitrogen has been tried. ${ }^{7}$

\subsection{Chemical Extraction Methods}

Wood fibers consists of cellulose hemicellulose and lignin, of which lignin impedes separation of wood into its component fibers. It is reasonable to delignificate at initial step for the extraction of NC. The kraft pulping process is the most commonly used method of lignin removal, which uses a hot solution of sodium hydroxide and sodium sulfide in a digester. ${ }^{8}$ Microcrystalline cellulose (MCC) can be used as intermediate source for the $\mathrm{CNF}$ and $\mathrm{CNC}$ extraction, of which most of the lignin and substantial amounts of hemicellulose already removed. ${ }^{9}$ Acid hydrolysis can effectively break the amorphous cellulose and extract $\mathrm{CNC}$ into the suspension. ${ }^{10}$ Fig. 3 shows the acid hydrolysis role for isolating CNC and its TEM image for sisal. ${ }^{11}$ Similar to the acid treatments, cellulose enzymes can attack on the amorphous regions of cellulose fibers, which make it easier to extract microfibrillated cellulose. ${ }^{12}$ Dissolution of cellulose is a method to swell microcrystalline cellulose, making it much more susceptible to separate into nanofibers. There are many kinds of cellulose solvent and

Table 1 Comparison of material properties of cellulose ${ }^{4}$

\begin{tabular}{ccccccc}
\hline Material & $\begin{array}{c}\text { Tensile } \\
\text { strength } \\
(\mathrm{GPa})\end{array}$ & $\begin{array}{c}\text { Young's } \\
\text { modulus } \\
(\mathrm{GPa})\end{array}$ & $\begin{array}{c}\text { Density } \\
\left(\mathrm{g} / \mathrm{cm}^{3}\right)\end{array}$ & $\begin{array}{c}\text { Tensile/ } \\
\text { density }\end{array}$ & $\begin{array}{c}\text { Modulus/ } \\
\text { density }\end{array}$ & $\begin{array}{c}\text { Thermal } \\
\text { exp. coe. } \\
(\mathrm{ppm} / \mathrm{K})\end{array}$ \\
\hline CNC & 7.5 & 145 & 1.6 & 4.7 & 90.6 & $3-22$ \\
\hline $\begin{array}{c}\text { Glass } \\
\text { fiber }\end{array}$ & 4.8 & 86 & 2.5 & 1.9 & 34.4 & 13 \\
\hline Steel wire & 4.1 & 207 & 7.8 & 0.5 & 26.5 & 15 \\
\hline Kevlar & 3.8 & 130 & 1.4 & 2.7 & 92.9 & -4 \\
\hline Graphite & 21 & 410 & 2.2 & 9.5 & 186 & $2-6$ \\
\hline CNT & $11-73$ & $270-970$ & 1.0 & $11-73$ & $270-970$ & - \\
\hline
\end{tabular}

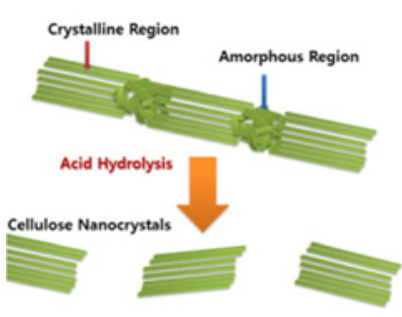

(a)

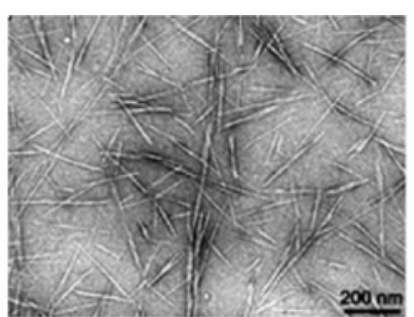

(b)
Fig. 3 (a) Acid hydrolysis breaks down disordered regions and isolates CNCs, and (b) TEM image of $\mathrm{CNC}^{11}$
$N, N$-dimethylacetamide (DMAc) with lithium chloride $(\mathrm{LiCl})$ is well known solvent for dissolving cellulose. ${ }^{13}$ Ionic liquid is a recyclable and environmentally friendly solvent that can dissolve cellulose. 1butyl-3-methylimidazolium chloride ionic liquid was used to dissolve and regenerate cellulose, which in turn was used for electro-active paper. $^{14,15}$ Electrospinning of cellulose solutions can be a way to extrude fine cellulose fibers. ${ }^{16}$ 2,2,6,6-tetramethylpiperidine-1-oxyl radical (TEMPO)-mediated oxidation under moderate conditions has been utilized for extracting 3-4 nm wide and a few microns long cellulose nanofibrils. ${ }^{17}$ When TEMPO-mediated oxidation is applied to native cellulose, the original fibrous morphologies are unchanged even after the oxidation, which is a regioselective surface modification of crystalline cellulose microfibrils.

\subsection{Mechanical Extraction Methods}

$\mathrm{CNF}$ is produce by delaminating inter-fibrillar hydrogen bonding of cellulose microfibers under intense mechanical forces in order to release CNF. Depending on the mechanical force levels and types, amorphous domains of cellulose or hemicellulose, sort of inter-fibrillar hydrogen bonding, can be easily broken at first and inter-molecular bonding by Van der Waals force can be broken secondly. Intramolecular hydrogen bonding of cellulose is rarely broken because of its high bonding strength. By breaking amorphous domains or interfibrillar hydrogen bonding, CNF can be extracted. A high pressure homogenizer and a grinding methods were attempted to micro fibrillate pulp fiber. ${ }^{18}$ The high pressure homogenizer has a spring-loaded valve which opens and closes in a reciprocating motion, subjecting the pulp to a large pressure drop and high shear and impact forces generated in a narrow slit of the valve. ${ }^{19}$ The grinder (MKCA6-3, Masuko Sangyou, Co., Ltd, Japan) has a specially designed disk for super-grinding such that by passing through a static grind stone and a rotating grind stone, shearing forces are applied to the pulp slurry. However, the treated pulp exhibited a wider distribution of fiber width. By combining two methods uniform CNF was formed. However, this CNF is so hydrophilic that its water retention increased to $534 \%{ }^{18}$ There are attempted methods to extract CNFs, for example bead mill, pearl mill, ball mill, dis mill and twin screw extruder.

Recently, an eco-friendly CNF extraction method was invented using aqueous counter collision (ACC). ${ }^{20-22}$ This method allows biobased materials to be processed into nano-objects using only a pair of water jets without any chemical modifications. Fig. 4 shows schematic of ACC method and TEM image of an extracted CNF. A single ACC pass can produce kinetic energy between $6.7-18.1 \mathrm{~kJ} / \mathrm{mol}$, which is
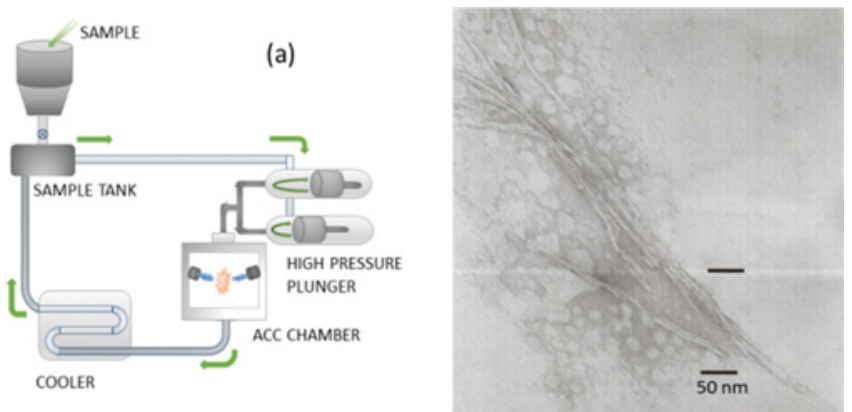

Fig. 4 (a) Schematic of ACC method and (b) TEM image of CNF 
more than the energies associated with dipole-dipole, London dispersion forces and weak hydrogen bonds. ${ }^{20}$ It is possible to effectively reduce the particle sizes of various polymeric materials with hierarchical structures, either natural or synthetic or carbon, using ACC method. Interestingly, ACC treated $\mathrm{CNF}$ exhibits hydrophilic and hydrophobic behaviors such that switching surface effect can be produced depending on the substrate surface behavior. ${ }^{22}$

\section{Engineering Composites}

\subsection{Influencing Factors on Mechanical Properties of NC-Based Composites}

\subsubsection{Sources of the CNFs}

The mechanical properties of celluloses vary by their natural sources as shown in Table 2. Cellulose fibers from the same sources also have some ranges of properties by changing their molecular level shapes and qualities. ${ }^{23}$ This variation may be caused by diverse growth environment for the plants as well as compositional ratio among cellulose, hemicellulose, and lignin. Furthermore, disintegration techniques also alter their aspect ratio and mechanical stiffness even from the same natural sources. Higher aspect ratio of filler materials usually increases both stiffness and stress transfer of composites while dispersion uniformity in the matrix becomes poorer. ${ }^{24}$

Stiffness of natural fibers such as cellulose are severely affected by crystallinity as well as molecular ordering while strength of the fiber improves both by increasing cellulosic contents and by decreasing spiral angle as shown in Fig. 5. Strength of the fibers is not highly dependent on the structural ordering but on the inner defects on the structures. ${ }^{24}$

\subsubsection{Processing Techniques for the CNF Composites}

Processing techniques for cellulose nanocomposites include solution-casting, melt-extrusion, electron-spinning, and beyond. ${ }^{25-31}$

Table 2 Comparison of mechanical properties of natural fibers ${ }^{23}$

\begin{tabular}{cccc}
\hline Fiber & $\begin{array}{c}\text { Tensile } \\
\text { strength(MPa) }\end{array}$ & $\begin{array}{c}\text { Elongation at } \\
\text { break(\%) }\end{array}$ & $\begin{array}{c}\text { Young's } \\
\text { modulus(MPa) }\end{array}$ \\
\hline Cotton & $264-654$ & $3.0-7.0$ & $4980-10920$ \\
\hline Wool & $120-174$ & $25-35$ & $2340-3420$ \\
\hline Silk & $252-528$ & $20-25$ & $7320-11220$ \\
\hline Flex & $300-900$ & $2.7-3.2$ & 24000 \\
\hline Jute & $342-672$ & $1.7-1.8$ & 43800 \\
\hline Sisal & $444-552$ & $2.0-2.5$ & - \\
\hline Ramie & $348-816$ & $3.6-3.8$ & 53400 \\
\hline
\end{tabular}
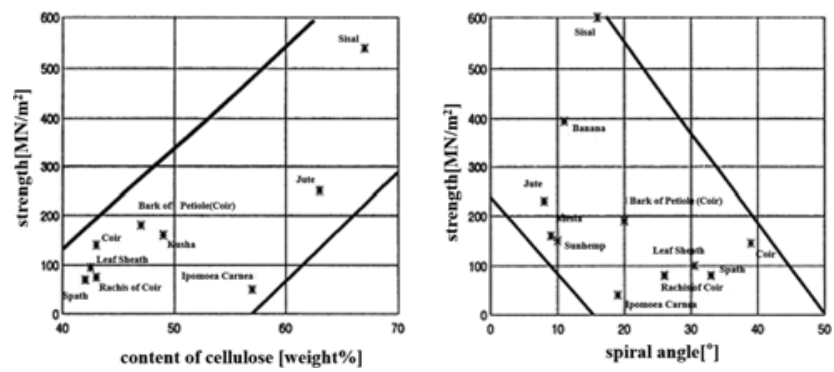

Fig. 5 Effect of the cellulose contents in natural sources and the spiral angle on strength ${ }^{24}$
Each method has unique pros and cons such as interaction between matrix and fibers, alignment of long fibers, stress transfer effectiveness, and dispersion of nanofibers in matrix. ${ }^{23}$ Also, processing parameters such as temperature, casting rate, molecular tension at the interfaces, loading ratio of cellulose nanofillers, and annealing treatments strongly influence the overall mechanical performances of the cellulose composites. Thus, choosing appropriate processing methods and conditions with wide ranges of celluloses and matrix materials is important for achieving the desired composite quality. ${ }^{23,32}$

One of the most common techniques for fabricating biopolymer is the solution casting because its process is cheap and simple. ${ }^{33}$ The solution casting techniques was compared with freeze-drying and hotpressing techniques for fabricating thermoplastic composites added with cellulose nanowhiskers. ${ }^{25}$ SEM images of their solution casted composites revealed some degree of cellulose aggregates and uneven cellulose distribution from top to bottom layers. This disparity might be originated from slow sedimentation of fillers and evaporation of solution. Surprisingly, reinforcement effects of this solution casted composite excel those of freeze casted and hot-pressed samples because slow sedimentation promotes rigid stress sharing networks formed by strong hydrogen interactions between celluloses. ${ }^{25}$ This high hydrophilicity of cellulose also causes problems during composite processing such as severe agglomeration in a non-polar matrix. ${ }^{34}$ This interactive exclusion from matrix is particularly serious combined with high aspect ratio of cellulose when cellulose contents rise above $20 \%$ in a composite. Thus, it is extremely difficult to fabricate homogeneous composites with more than $20 \%$ cellulose loading by simply mixing raw ingredients. ${ }^{26}$

One way to reduce this agglomeration is a melt extrusion technique which involves high yield pumping extrusion of polymer melts such as $\mathrm{PLA}^{33}$ together with suspension of NCs. ${ }^{34}$ Processing techniques for high strength PLA-CNF composites through twin-extruder have been reported. ${ }^{27,28}$ The melt processing conditions include temperature, cellulose loading, mixing time and rate, fiber orientation governed the mechanical properties of the polypropylene (PP)-cellulose composites. For example, in the temperature under $T_{g}$, the viscosity of the compounds becomes too high to flow and extremely high shear stresses are simultaneously exerted on the CNFs. These stresses severely cut the fibers and lower the aspect ratio of CNFs. In the other extreme temperature, the cellulose nanofibers become degraded. Thus, the mechanical properties of the composite have peaks in the narrow optimized temperatures. Furthermore, higher loading of CNF enables faster stress transfer between matrix and filler fibers by increased attraction, which improved elastic modulus and strengths of the composites. Mixing rate of the $\mathrm{CNF}$ also changed the orientation degree as well as dispersion uniformity. As shown in Fig. 6, orientation of the CNFs plays critical roles in the mechanical performances. If the CNFs are situated in the transverse direction with the external stresses, the exerting stresses are not effectively transferred or distributed toward CNFs. This imbalance generates even degrading mechanical performances by adding CNF reinforcements. ${ }^{23}$

Electrospining is a technique for fabricating few microns to hundreds $\mathrm{nm}$ diameter polymeric fibers by electrostatic forces. This electrospun fiber has superior features such as large surface area, controllable porosity, and macro level flexibility. ${ }^{35}$ Electrospun PEO-CNC composites were demonstrated. ${ }^{35}$ As the diameter of the injection needle decreased and the 
contents of electrostatically charged cellulose increased, the uniformity of the diameters of the electrospun composite fibers increased. The distribution and alignment of $\mathrm{NC}$ inside the composite fibers were also decent to possess acceptable mechanical performances.

\subsubsection{Surface Modification}

Intrinsically celluloses are hydrophilic which hampers interfacial compatibility with most hydrophobic polymer matrices. Thus, surface treatments by various coupling agents have been employed to lower the interfacial associative tensions for years. By reforming hydrophobic surfaces on the NCs, interfacial wetting and interactions with commodity polymer matrices were improved to result higher mechanical performances. ${ }^{26,36}$ Maleic anhydride grafted coupling agent (MAPP) was used to process PP - CNF composites, which showed more than $50 \%$ increment of the mechanical strength. ${ }^{26}$

\subsection{Environment-Friendly NC-Reinforced Composites \\ 3.2.1 Mechanical Property}

Biopolymers such as chitosan, PLA, starch, have been widely used to make cellulose composites because these biopolymers can make the whole composite biodegradable and eco-friendly by avoiding resources from fossil fuel. Biopolymer itself usually has poor mechanical properties compared to those of synthetic polymers so that their applications were limited to commodity products. Thus, reinforcing nanomaterials without sacrificing environmental advantages of biopolymers have been searched to improve mechanical versatility. ${ }^{37}$

CNFs are one of the most superior reinforcing materials to biopolymers because of their inherent biocompatibility, renewability, biodegradability, and universality. Unlike carbonaceous materials including carbon nanotubes, graphite, and graphene, ${ }^{38} \mathrm{CNFs}$ can be functionalized without breaking molecular backbone structures, which facilitate uniform dispersion or strong binding to matrix in polymeric composites. The core attributes of CNFs as reinforcements include extremely high specific stiffness as well as high aspect ratio (diameter/ length), which promote efficient load bearing transfer from matrix to reinforcing CNF phase. ${ }^{39}$ Thus, combined with high mechanical properties, CNFs have been highlighted as eco-friendly reinforcement materials for transforming from weak biopolymers to strong engineering biocomposites for around 20 years after long CNFs were extracted from tunicates. ${ }^{40}$ Table 3 presents examples of biodegradable polymer-CNF nanocomposites and their mechanical properties with CNF content.
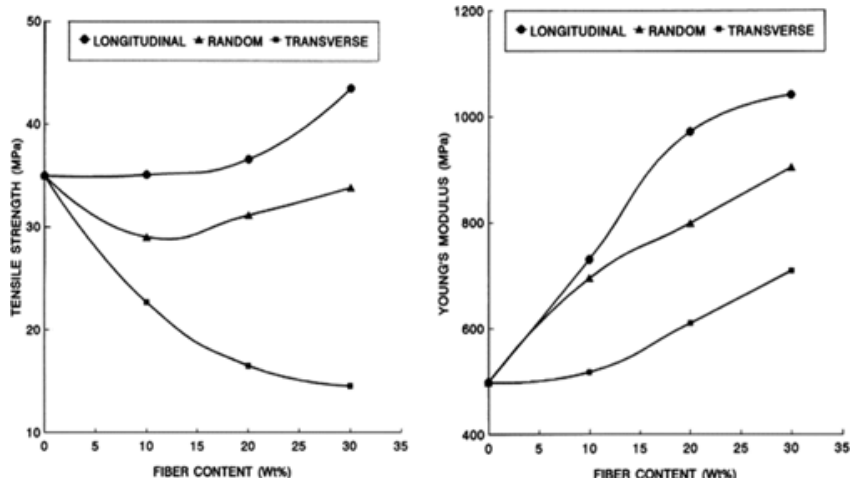

Fig. 6 Effect of CNF orientation on tensile strength and Young's modulus $^{23}$

\subsubsection{Poly(vinyl alcohol) - CNF Composites}

Poly(vinyl alcohol) (PVA) is a synthetic biodegradable polymer whose unique properties include thermoplastic, water-soluble, semicrystalline, nontoxic, transparent, and bio-compatible. ${ }^{44}$ Hydroxyl functional groups on both PVA and CNF make PVA popular matrix candidates on CNF composites. Furthermore, many successful reinforcement studies on CNF - PVA composites were reported as in

Table 3 Examples of biodegradable polymer-CNF nanocomposites and their mechanical properties with CNF content

\begin{tabular}{|c|c|c|c|c|c|c|}
\hline Matrix & $\begin{array}{l}\text { Cellulose } \\
\text { (resource) }\end{array}$ & $\begin{array}{c}\text { Content } \\
(w t \%)\end{array}$ & $\begin{array}{c}\text { Tensile } \\
\text { strength } \\
(\mathrm{MPa})\end{array}$ & $\begin{array}{c}\text { Young's } \\
\text { modulus } \\
(\mathrm{GPa})\end{array}$ & Process & Ref. \\
\hline \multirow{7}{*}{$\begin{array}{c}\text { Poly } \\
\text { (vinyl } \\
\text { alcohol) }\end{array}$} & $\begin{array}{c}\text { CNF } \\
\text { (curava) }\end{array}$ & 5 & $\sim 80^{*}$ & $\sim 1.6^{*}$ & $\begin{array}{c}\text { Solution } \\
\text { casting }\end{array}$ & 41 \\
\hline & $\begin{array}{l}\text { CNF } \\
\text { (flax) }\end{array}$ & 5 & 33.07 & 0.536 & & 42 \\
\hline & $\begin{array}{l}\text { CNF } \\
(\mathrm{MCC})\end{array}$ & 5 & $\sim 80^{*}$ & $\sim 4^{*}$ & & 43 \\
\hline & $\begin{array}{l}\mathrm{CNF} \\
\text { (pulp) }\end{array}$ & 60 & 55.6 & 1.022 & & 44 \\
\hline & $\begin{array}{c}\mathrm{CNF} \\
\text { (banana) }\end{array}$ & 3 & 46 & 2.940 & & 45 \\
\hline & $\begin{array}{c}\mathrm{CNF} \\
\text { (aloe vera) }\end{array}$ & 10 & $\sim 160^{*}$ & 7.99 & & 46 \\
\hline & $\begin{array}{c}\text { CNF } \\
\text { (cotton) }\end{array}$ & 5 & 1890 & 42 & $\begin{array}{c}\text { Gel } \\
\text { spinning }\end{array}$ & 47 \\
\hline \multirow{7}{*}{$\begin{array}{l}\text { Poly } \\
\text { (lactic } \\
\text { acid) }\end{array}$} & $\begin{array}{l}\text { CNF } \\
\text { (flax) }\end{array}$ & $2.5-5.0$ & $19.4-30.9$ & $1.48-2.17$ & $\begin{array}{c}\text { Solution } \\
\text { casting }\end{array}$ & 48 \\
\hline & $\begin{array}{l}\text { MCC } \\
\text { (pulp) }\end{array}$ & 20 & 38.1 & 4.7 & \multirow{5}{*}{ Extrusion } & 49 \\
\hline & $\begin{array}{l}\text { CNF } \\
\text { (pulp) }\end{array}$ & 5 & 71.2 & 3.6 & & 27 \\
\hline & $\begin{array}{c}\text { CNF } \\
\text { (bamboo) }\end{array}$ & \multirow{3}{*}{2} & 53 & 2.2 & & \multirow{3}{*}{50} \\
\hline & $\mathrm{BC}$ & & 57 & 2.3 & & \\
\hline & $\mathrm{MCC}$ & & 71 & 2.6 & & \\
\hline & $\begin{array}{l}\text { CNF } \\
\text { (pulp) }\end{array}$ & 10 & 75 & 4.7 & Kneading & 51 \\
\hline \multirow{5}{*}{$\begin{array}{c}\text { Poly } \\
\text { (ethylene } \\
\text { oxide) }\end{array}$} & $\begin{array}{l}\mathrm{CNC} \\
(\mathrm{MCC})\end{array}$ & 20 & 8.52 & 0.0596 & \multirow{3}{*}{$\begin{array}{l}\text { Electro- } \\
\text { spinning }\end{array}$} & 35 \\
\hline & $\mathrm{CNC}$ & 1 & 3.5 & 0.072 & & \multirow{2}{*}{52} \\
\hline & $\mathrm{CNF}$ & 4 & 2.2 & 0.051 & & \\
\hline & $\mathrm{CNC}$ & 7 & 17.6 & 0.937 & Solution & 53 \\
\hline & $\mathrm{CNF}$ & 7 & 27.3 & 1.727 & casting & 53 \\
\hline \multirow{2}{*}{ Chitosan } & $\mathrm{CNF}$ & 10 & 57.45 & 1.627 & \multirow{2}{*}{$\begin{array}{c}\text { Solution } \\
\text { casting }\end{array}$} & 37 \\
\hline & $\mathrm{CNC}$ & 5 & 99 & 2.971 & & 54 \\
\hline \multirow{2}{*}{ Starch } & $\begin{array}{c}\mathrm{CNC} \\
\text { (rice straw) }\end{array}$ & 10 & 26.8 & 0.898 & \multirow{2}{*}{$\begin{array}{c}\text { Solution } \\
\text { casting }\end{array}$} & 55 \\
\hline & $\begin{array}{c}\mathrm{CNC} \\
\text { (kneaf) }\end{array}$ & 6 & 8.2 & 0.326 & & 56 \\
\hline \multirow{3}{*}{$\begin{array}{l}\text { Soy } \\
\text { protein }\end{array}$} & $\begin{array}{c}\mathrm{CNF} \\
\text { (cotton) }\end{array}$ & 20 & 31.19 & 1.023 & \multirow{2}{*}{$\begin{array}{l}\text { Solution } \\
\text { casting }\end{array}$} & 57 \\
\hline & $\mathrm{CNF}$ & 30 & 59.3 & 1.816 & & 58 \\
\hline & $\begin{array}{c}\text { CNF } \\
\text { (soy chaff) }\end{array}$ & 5 & 10.83 & 0.172 & $\begin{array}{c}\text { Hot } \\
\text { solution } \\
\text { casting }\end{array}$ & 59 \\
\hline
\end{tabular}

CNF: Cellulose nanofiber, CNC: Cellulose nanocrystal, MCC: microcrystalline cellulose, $\mathrm{BC}$ : bacterial cellulose, *: values estimated from charts presented in the original reference 
Table 3. The addition of just 5\% CNFs to PVA doubled the Young's modulus of the polymer and increased tensile strength $\left(S_{t}\right) .{ }^{42} \mathrm{CNF}$ was isolated from curava and prepared PVA-CNF composites by solution casting. With $5 \%$ of $\mathrm{CNF}$ contents, $E$ and $S_{t}$ of the composites increased by $44 \%$ and $450 \%$ compared to neat PVA, respectively. ${ }^{41}$ The $S_{t}$ and $E$ of PVA-CNF composites, whose CNFs were derived by acid hydrolysis of microcrystalline cellulose (MCC), increased nearly proportional to CNF content up to $7 \%$. CNF was isolated from pulp by means of mechanical grinding and high pressure homogenization without any chemical treatments, and the highest $S_{t}$ and $E$ were observed at $60 \%$ CNF content. ${ }^{44}$ Highly oriented fibers of PVAcellulose whiskers were prepared by gel spinning. The composites exhibited superior mechanical properties as shown in Fig. 7, 1.89 GPa $\left(S_{t}\right)$ and $42 \mathrm{GPa}(E)$ which might be cause by anisotropic alignment of whiskers in the composite fibers. ${ }^{47}$ Overall, we found that there is huge variation in effectiveness of reinforcements by CNFs in PVA matrix. Possible factors for this variation include pretreatment, alignments, isolation, and chemical functionalization of CNFs as well as composite processing conditions and natural sources of $\mathrm{CNFs}^{46}$

\subsubsection{Poly(lactic acid) - CNF Composites}

Poly(lactic acid) (PLA) is a renewable thermoplastic biopolymer made from agricultural materials like corn, via lactic acid fermentation. The versatility of PLA is exemplified by wide range of applications in packaging, consumable goods, automotive parts, 3D printing, and biomedical implants. ${ }^{48}$ The major shortcomings with PLA properties include weak toughness and low thermal stability. Thus, active researches are going on to improve the shortcomings of PLA by incorporating reinforcing fillers such as NC. ${ }^{49} \mathrm{CNFs}$ were obtained from flax yarn by acid hydrolysis and then PLA-CNFs composites were prepared by solution casting. $E$ and $s$ of the composites with 5\% CNF increased by $47 \%$ and $59 \%$ compared to pure PLA. ${ }^{48}$ An enhanced thermal stability of the composites was shown in Dynamic mechanical thermal analysis (DMTA) curves (Fig. 8). ${ }^{49}$ Comparison on cellulose sources was also performed among bacterial cellulose (BC), MCC and bamboo cellulosic fibers (BCFs) (Fig. 9). Although all of them increased stiffness of PLA composites, MCC showed the highest increment by efficient load bearing transfer. ${ }^{50}$ Reinforcing efficacy of microfibrillated cellulose (MFC) in PLA matrix was studied. ${ }^{51}$ Uniformly dispersed MFC increased $E$ and $s$

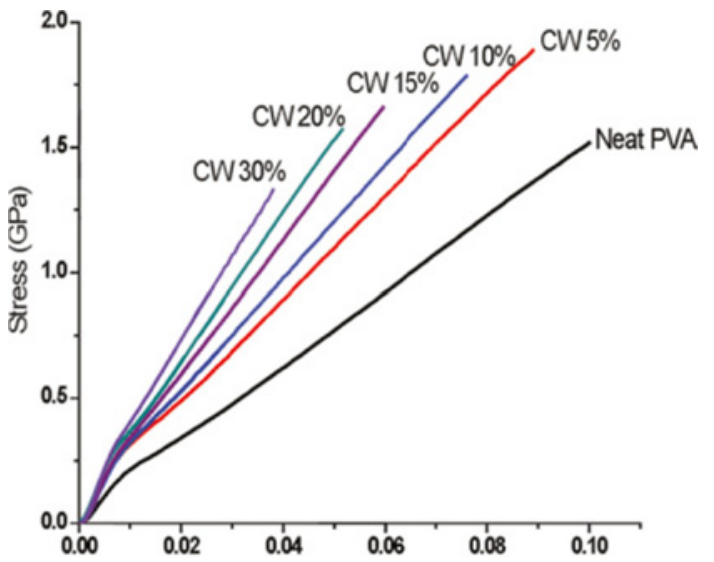

Fig. 7 Stress-Strain curves of PVA-cellulose whisker nanocomposites by gel spinning ${ }^{47}$ of the composites by $40 \%$ and $25 \%$ respectively without a reduction of yield strain up to MFC content of $10 \%$ as shown in Fig. 10.
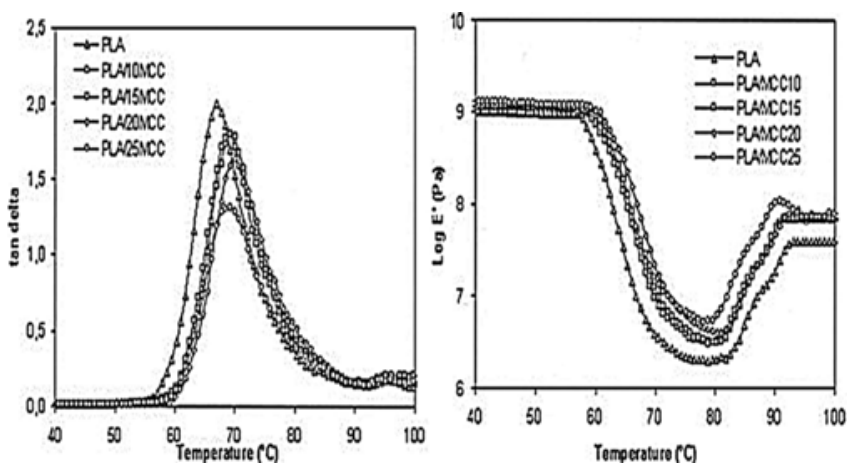

Fig. 8 DMTA graphs of PLA based composites with different concentration of $\mathrm{MCC}^{49}$

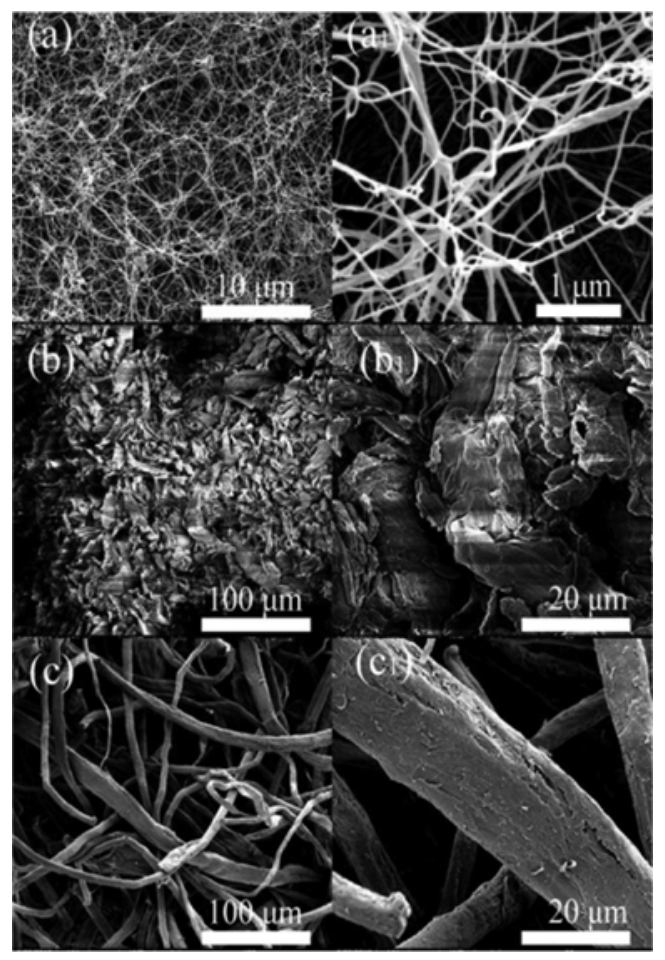

Fig. 9 Scanning electron microscopy (SEM) images of (a), (a1): BC; (b), (b1): MCC; (c), (c1): cellulosic fiber from bamboo ${ }^{50}$

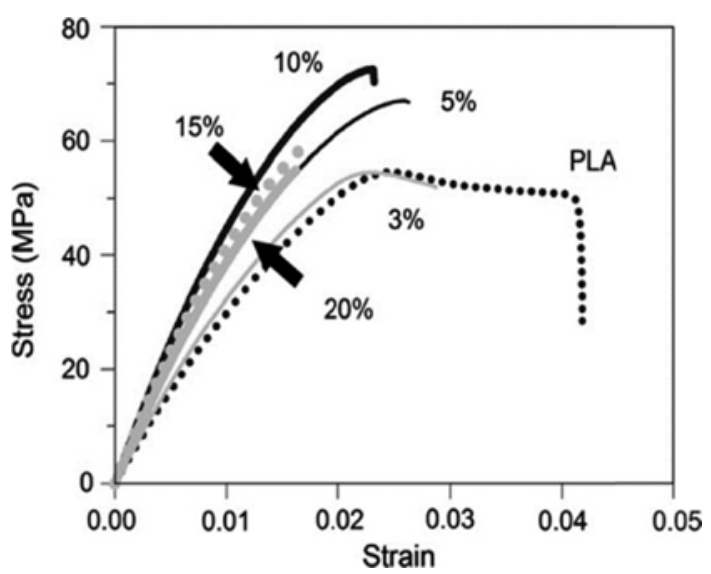

Fig. 10 Stress-Strain curves of PLA- MFC with different contents of MFC ${ }^{51}$ 


\subsubsection{Poly(ethylene oxide) - CNF Composites}

Poly(ethylene oxide) (PEO) is a biodegradable, biocompatible, hydrophilic, and flexible polymer, which innately forms hydrogen bonding with cellulose. PEO is used as polyelectrolytes in the battery application, and also broadens its usability in the biomedical application as drug delivery carriers or biocompatible scaffolds. ${ }^{60}$ For expanding the application of PEO, seamless reinforcements with $\mathrm{NC}$ are continually reported. Electrospun PEO composite fibers containing CNCs were produced, which were hydrolyzed by acid from MCCs. $E$ and $S_{t}$ of the $20 \%$ CNC composites were improved by 2.5 and 2 times from those of the pure PEO, respectively, and its improvement were nearly linear with $\mathrm{CNC}$ content (Fig. 11). ${ }^{35}$ Recently, difference of CNCs and CNFs in reinforcing efficiencies of electrospun PEO nanofibers was reported. ${ }^{52}$ Although $1 \%$ of CNCs and $4 \%$ of CNFs showed the highest $E$ and $S_{t}$, the composite fibers became too brittle and lowered toughness as further increasing their fillers. When they changed the PEO composite processing to solvent casting, $7 \%$ of the cellulose fillers was the optimum loading unlike electrospinning PEO composite. ${ }^{53}$

\subsubsection{Chitosan - CNF Composites}

Chitosan is one of the polysaccharides derived by deacetylation of chitin, ${ }^{37}$ whose property include non-toxic, biodegradable, and biocompatible. $^{54}$ The effects of varying concentrations of CNF and glycerol (plasticizer) in chitosan indicated that the mechanical properties were the highest with $5 \% \mathrm{CNF}$ content. ${ }^{37}$ Only small loading of NCC could reinforce chitosan because efficient stress transfer were restricted by formation of penetration on networks and interaction between fillers and matrices. ${ }^{54}$

\subsubsection{Starch - CNF Composites}

Starch is one of the most widely used biopolymers because its availability. ${ }^{55}$ The isolation of CNCs from rice straw and its application as reinforcing filler in starch-based bioplastic were reported. $E$ and $S_{t}$ of the starch composite significantly increased by about 1.5 and 2 times, respectively with $10 \% \mathrm{CNC}$ loading. ${ }^{55} \mathrm{CNCs}$ were extracted from kenaf fibers as reinforcing fillers in starch. From the tensile tests, it was found that $6 \%$ of CNCs are enough to improve the mechanical quality of the composites. ${ }^{56}$

\subsubsection{Soy Protein - CNF Composite}

Soy bean is also one of the renewable materials, which is

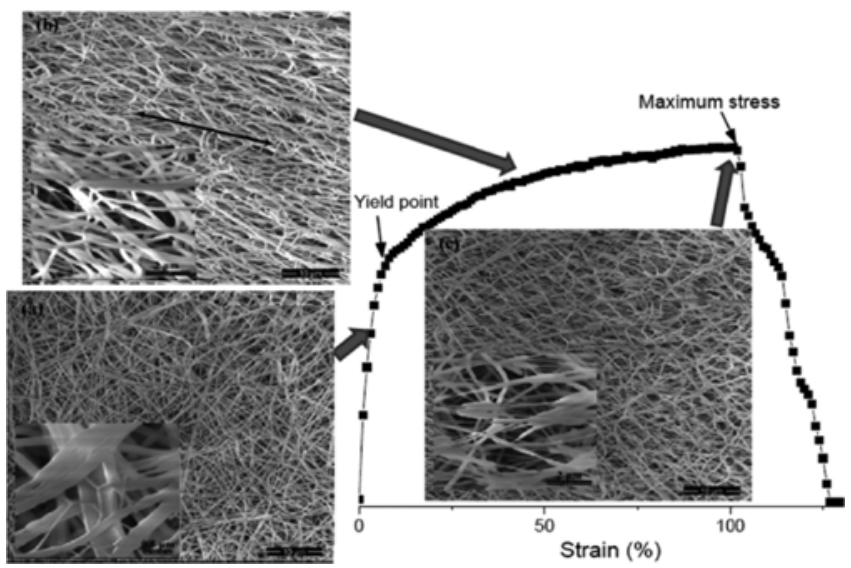

Fig. 11 SEM images of PEO-CNC composites during tensile test ${ }^{35}$ biodegradable, low cost and plentiful in production, and widely available. Thus, this soy protein can be used to make eco-friendly consumable bioplastics. ${ }^{58}$ Mechanical properties of soy protein thermoplastics can be changed by adding cellulose nanowhiskers (CNWs).$^{57}$ Because phase separation happened with a high relative humidity (RH) condition, they tested the composite at $0 \% \mathrm{RH}$ at which $E$ and $S_{t}$ changed from $0.53 \mathrm{GPa}$ to $1.02 \mathrm{GPa}$ and from $16.7 \mathrm{MPa}$ to $31.2 \mathrm{MPa}$, respectively by filling $20 \% \mathrm{CNWs}$. When micro/nano-sized bamboo fibrils (MBF) were used to make cellulose - soy protein plastics, $E$ and $S_{t}$ changed from $0.60 \mathrm{GPa}$ to $1.82 \mathrm{GPa}$ and from 20.2 MPa to $59.3 \mathrm{MPa}$, respectively with $30 \%$ cellulose. $^{58}$

\subsubsection{Barrier Property}

The materials for packaging applications is mostly petroleum based non-biodegradable polymers because of exceptional gas and water barrier properties, and low cost. As environmental issues about reducing wastes and saving resources are continuously brought, more societal pressures are being imposed to replace the sources of these food packaging polymers from fossil fuels to eco-friendly sustainable biomaterials. Furthermore, these conventional polymers are neither easily degradable nor recyclable once they are processed to composites, thus causing environmental pollution. However, the barrier properties of the biopolymers are not as perfect as conventional packaging materials petroleum based polymers like PP. Thus, controlled or limited permeability of low molecular gases to biopolymers have been actively developed. One factor for controlling barrier properties is increasing crystallinity of the biopolymers. ${ }^{61} \mathrm{In}$ order to enhance the crystallinity, nanomaterials such as NC were tried to add in biopolymers while maintaining their inherently good properties such as transparency and biodegradability. ${ }^{62}$ The barrier properties of paper could be improved by adding MFC extracted from wood. This improved barrier properties were caused by decreasing densities of surface micro-pores. ${ }^{61}$ Also, it is known that CNWs were able to reduce the water and oxygen permeability by up to $82 \%$ and $90 \%$, respectively with $3 \mathrm{wt} \%$ of $\mathrm{CNW}^{62} 5 \% \mathrm{NCC}$ addition on chitosan could reduce the water vapor permeability to $27 \% .{ }^{55}$ More recently, adding CNFs on biodegradable PEOs increased gas barrier properties. By simple solvent casting, crystalline orientation of PEO was improved (Fig. 12) as well as permeation wall to gas were effectively formed by $5 \% \mathrm{CNF}$ addition. ${ }^{63}$

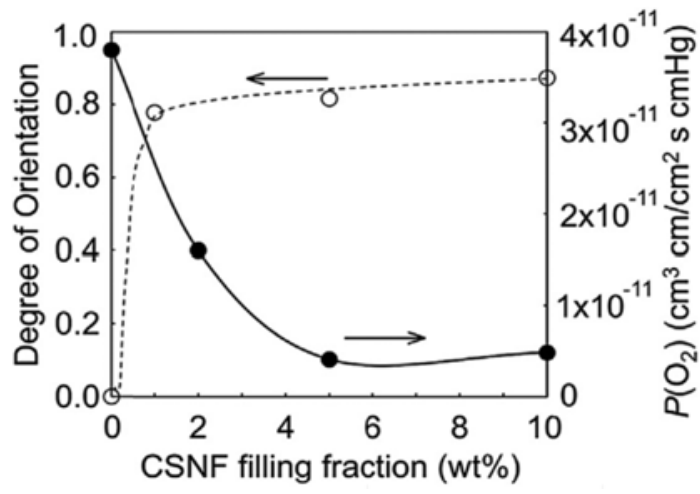

Fig. 12 The degree of crystallite orientation and oxygen permeability with different CNFs contents in PEO-CNFs composites ${ }^{63}$ 


\section{Smart Materials and Structures}

$\mathrm{NC}$ based smart materials display intelligent behavior in response to environmental stimuli such as light, temperature, electrical input, $\mathrm{pH}$, and magnetic force, to design smart materials for many applications. ${ }^{64-67}$ Due to biocompatible and biodegradable nature, cellulose based stimuliresponsive materials have shown great potential in electro-stimulated targeted drug delivery systems. ${ }^{68,69} \mathrm{CNCs}$ with high aspect ratio and mechanically stiff fibers can serve as renewable reinforcing agents in nanocomposites, as well as a handle for adding stimuli responsiveness. ${ }^{70}$ $\mathrm{CNF}$ photo-responsive nature can act as an adaptive filler in a soft polymer matrix, and can also act as a photo-switchable gelator. ${ }^{71}$ The exceptional characteristics of NC such as low density, thermal stability, chemical resistance, high mechanical strength, biocompatibility and bio degradability has allowed to use it as functional material in actuation systems, and sensors for detecting $\mathrm{pH}$, organic vapors, ions and humidity. In the last five years, research on $\mathrm{NC}$ has increased extensively to design nanostructured materials, like $\mathrm{CNC}, \mathrm{CNF}$, and BC. Cellulose itself has limited functionalities in smart materials and structures, but three-dimensional hierarchical structure that contains cellulose nanofibers or nanoparticles has broadened its opportunities.

\subsection{Cellulose Based Actuators}

The interesting actuation mechanism and piezoelectricity exhibited by cellulose has broaden the development in the area of cellulose research. ${ }^{65}$ Cellulose based electro-active paper (EAPap) has been employed in many smart applications including electromechanical transducers, actuators, and for haptic applications. ${ }^{72-75}$ To improve the performance, cellulose based EAPap actuators has been characterized with ionic liquids, conducting polymer, SWNT/MWNT, chitosan blends, and metal oxide cellulose nanocomposites. Yang et al. fabricated a wirelessly driven Cellulose-Polypyrrole-Ionic Liquid (CPIL) nanocomposite actuator by incorporating nanoscale polypyrrole onto cellulose by an in situ polymerization technique followed by activation in a room temperature ionic liquid (Fig. 13) ${ }^{76}$ The CPIL

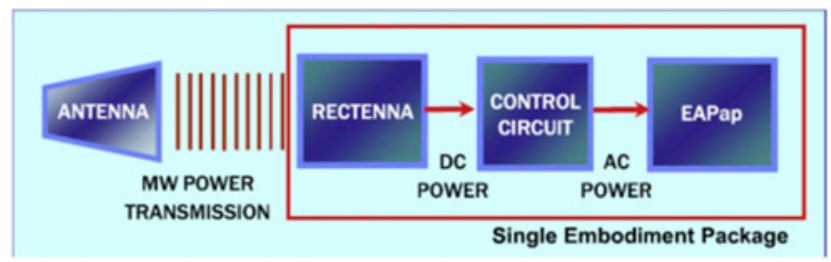

(a)

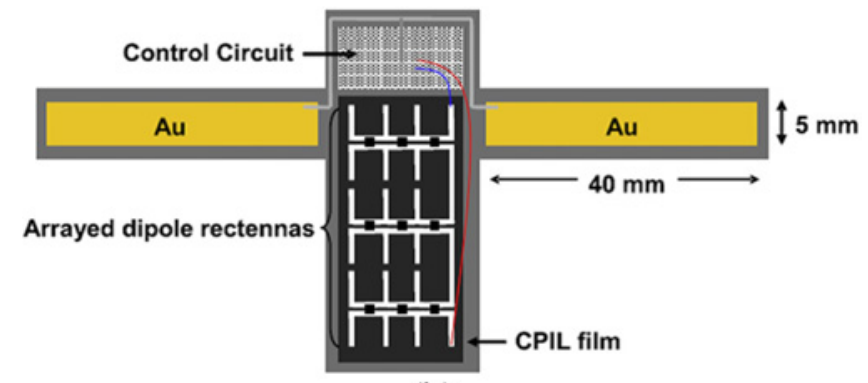

(b)

Fig. 13 (a) Concept of wirelessly driven EAPap actuator, and (b) Configuration of wirelessly driven CPIL actuator ${ }^{76}$ actuator showed a maximum bending displacement of $10 \mathrm{~mm}$ under ambient humidity conditions with an electrical power consumption of $30 \mathrm{~mW}$. The concept of a remotely powered and controlled EAPap actuator by means of modulating waves with a control signal, and demodulating the actuator through the rectenna (rectifying antenna) rectification was investigated. Without microwave modulation, the maximum voltage and power obtained from the dipole rectenna array were $11.4 \mathrm{~V}$ and $324 \mathrm{~mW}$, respectively. With modulated microwaves, the maximum output voltage and power were slightly increased to $12.8 \mathrm{~V}$ and $410 \mathrm{~mW}$, respectively. ${ }^{77}$ The performance of a bending electro-active paper actuator made by mixing MWNTs and cellulose was tested in terms of its electrical input, mechanical power output and resonance frequency ${ }^{78}$ Functionalized multi-walled carbon nanotubes (F-MWNTs) were blended with cellulose solution to fabricate FMWNTs/cellulose EAPap actuators, resulting in a large bending displacement of $4.5 \mathrm{~mm}$ and improved output force. ${ }^{79}$ Cellulose EAPap is sensitive to humidity and temperature and its electromechanical behavior degrades with time. An attempt was made to eradicate these pitfalls by cracking an EAPap actuator made with cellulose and chitosan blends. ${ }^{80}$ The results showed that the chitosan-cellulose-based EAPap actuator is less sensitive to humidity; a large bending displacement of about $4.1 \mathrm{~mm}$ and long lifetime were noticed.

The material properties of cellulose for smart applications can be enhanced by adding metal oxide to the cellulose matrix. ${ }^{81} \mathrm{~A}$ high strength elastomeric nanocomposite was prepared by dispersing microcrystalline cellulose in a polyurethane matrix. ${ }^{82}$ The resulting large improvements in the stiffness/strength, as well as strain-to-failure, were supposed to be due to the good interaction, caused by both covalent and hydrogen bonds, between the polyurethane and the cellulose nanofibrils. A $\mathrm{TiO}_{2}$-cellulose nanocomposite was synthesized through titanyl sulfate hydrolysis in an acidic medium in the presence of cellulosic fibers. ${ }^{83}$ By hybridizing functional metal oxides with cellulose substrates, nature friendly, cost effective and disposable sensor devices with good sensing performance are possible. A cellulose nanocomposite with high content of $\mathrm{Fe}_{3} \mathrm{O}_{4}$ nanoparticles with regenerated cellulose as a matrix provided a green and facile method for the preparation of bio-based nanocomposite films with excellent magnetic properties. ${ }^{84} \mathrm{~A}$ hybrid thin film consisting of tin oxide nanoparticles and cellulose was fabricated and characterized. ${ }^{85}$ The reduction in the crystalline melting transition temperature due to the $\mathrm{SnO}_{2}$ nanoparticles showed the potential application of this hybrid configuration as a biodegradable and flexible humidity sensor. The electromechanical behavior of the green cellulose- $\mathrm{ZnO}$ hybrid nanocomposite showed superior piezoelectric charge constant, with a value of $160 \mathrm{pC} / \mathrm{N}^{86}$

\subsection{Cellulose Based Hybrid Nanocomposites}

With the discovery of cellulose as a smart material, its use for paper based actuators and sensors has been reality. An amperometric glucose biosensor was utilized based on gold nanorods/cellulose acetate composite film as an immobilization matrix. ${ }^{87}$ Under optimal conditions, the biosensor showed high sensitivity $\left(8.4 \mu \mathrm{A} / \mathrm{cm}^{2} \mathrm{mM}\right)$, a low detection limit, and good storage stability. A glucose biosensor was developed based on cellulose paper and glucose oxidase immobilized cellulose- $\mathrm{SnO}_{2}$ hybrid nanocomposite (Fig. 14) ${ }^{88}$ 
Cellulose based hybrid nanocomposites have also been employed for the detection of toxic and harmful gases in gas sensors, and chemical vapor sensors ${ }^{89}$ Highly sensitive gas sensors were developed based on SWNT networks prepared from aqueous hydroxypropyl cellulose-assisted dispersions. ${ }^{90}$ The sensor can detect the level of 25 ppb or lower concentrations of $\mathrm{NO}_{2}$ and 5 ppm ammonia, and showed almost no baseline drift after multiple $\mathrm{NO}_{2}$ exposures at room temperature. A SWNT based ammonia sensor was reported with cellulose paper. ${ }^{91}$ Two types of devices were compared: CNT-on-paper and CNT-cellulose composite. The CNT-on-paper device showed a faster response/recovery and higher sensitivity than the CNT-cellulose composite, due to the larger reaction surface. In comparison to the control sensor made on a glass substrate, the paper based sensor exhibited superior uniformity and repeatability and can be utilized for smart paper based low-cost disposable applications. A robust capacitive humidity sensor was manufactured using a mixture of three cellulose acetate butyrates cross-linked by a melamine formaldehyde resin as the sensor material. ${ }^{92}$ The sensor showed good performance from 0 to $100 \% \mathrm{RH}$ and from -40 to $120^{\circ} \mathrm{C}$, and was robust enough to use in industrial processes. The increased piezoelectricity of cellulose EAPap due to mechanical stretching proved that the flexible regenerated piezoelectric cellulose can be applied to make a film type flexible cellulose-EAPap speaker in the audible range for acoustic applications. ${ }^{93}$

$\mathrm{CNC}$, and $\mathrm{CNF}$ have attracted large attention in nanostructures materials mainly due to their origin and properties like stiffness, nontoxicity, low thermal coefficient, transparency, and improved mechanical properties. ${ }^{70,94}$ These nanostructure materials have the potential to replace petrochemical based products and are extremely cheap compared to other high performance materials. A SEM image of raw cotton fibers revealed flat twisted ribbon form characteristic of the dried fibers, which was used in the characterization of a thin transparent nanopaper field effect transistor (FET). ${ }^{95}$ Inorganic nanoparticles, metal oxides and ions, graphene and graphene oxides, conducting polymers, carbon nanotubes and ionic liquids can be characterized with cellulose nanocrystals to produce cellulose based smart nanocomposites with better electrical and optical properties. ${ }^{96}$ The inherited piezoelectric effect of $\mathrm{CNC}$ thin films further extend its possibilities and potential. The relationship between polarization

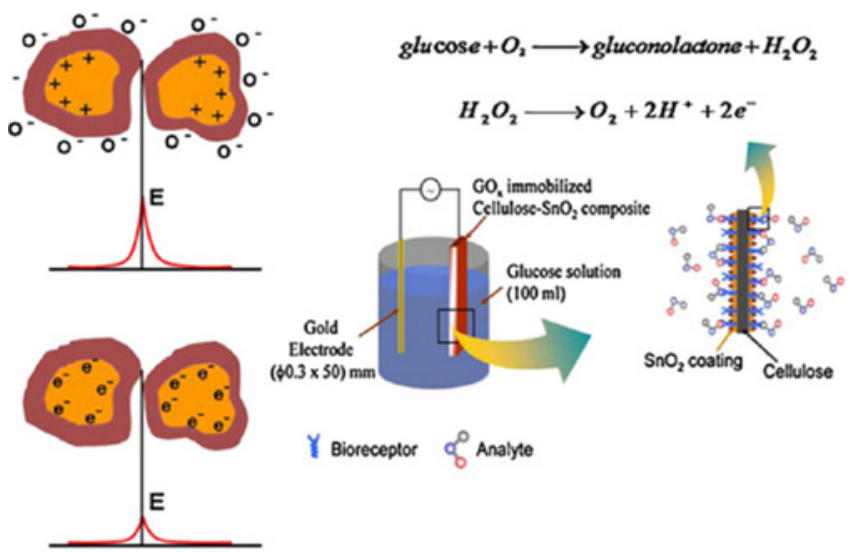

Fig. 14 Schematic of the detection mechanism of a cellulose- $\mathrm{SnO}_{2}$ hybrid nanocomposite glucose biosensor ${ }^{88}$ gradients and strain mechanics of ultra-thin films of aligned $\mathrm{CNC}$ was investigated by monitoring their deflections with an atomic force microscope in contact mode Fig. (15). The magnitude of shear piezoelectric constant $\left(d_{25}\right)$ was comparable to that of a piezoelectric metal oxide $(\mathrm{ZnO})$ film. ${ }^{97}$

\subsection{NC Based Smart Composites}

$\mathrm{NC}$ smart composites can form stimuli responsive materials for sensory and actuation applications, devices for electro-stimulated drug release, and biocompatible energy harvesting. CNCs have been widely used as reinforcement in shape memory materials, which changes their shape upon external stimulus. ${ }^{98} \mathrm{CNCs} / \mathrm{PU}$ composites showed higher tensile modulus and strength than unfilled films (53\% modulus increase at $1 \mathrm{wt} . \% \mathrm{NC})$, with higher elongation at break. Creep deformation decreased as cellulose concentration increased (36\% improvement se in 60 -minute creep by addition of $1 \mathrm{wt} \% \mathrm{NC}$ ). The rigidity of shape memory polymers by adding small amounts of well-dispersed $\mathrm{NC}$ was improved significantly. A stimuli-responsive mechanically adaptive CNCs nanocomposite was inspired by biological sea cucumbers, which has the potential to reversibly change the stiffness of their dermits. ${ }^{99}$ $\mathrm{CNCs}$ has been effectively employed in thermo, $\mathrm{pH}$, and mageneticresponsive nanocomposite for many potential applictions. ${ }^{100}$ Nanocomposites of poly(vinylacetate) (PVAc) and cotton cellulose whiskers demonstrates a mechanically adaptive behavior in response to thermal and chemical stimuli. ${ }^{101}$ The mechanical contrast in stiffness is almost similar to earlier generation PVAc-tunicate whisker nanocomposites. However, the water uptake of these nanocomposites is significantly lower, presumably due to the lower surface charge density of cotton cellulose whiskers films. Functionalization of the surface of $\mathrm{CNCs}$ was made by either carboxylic acid $\left(\mathrm{CNCCO}_{2} \mathrm{H}\right)$ or amine $\left(\mathrm{CNCNH}_{2}\right)$ pH-responsive. ${ }^{102}$ At low $\mathrm{pH}$, where the amine groups are protonated, $\mathrm{CNCNH}_{2}$ forms aqueous dispersions in water on account of electrostatic repulsions of the ammonium moieties inhibiting aggregation. However, a transition to hydrogels is observed at higher $\mathrm{pH}$ where the $\mathrm{CNCNH}_{2}$ are neutral and the attractive forces based on hydrogen bonding dominate. It was further explained that $\mathrm{pH}$ responsive CNCs can be incorporated into a PVAc matrix to yield mechanically adaptive $\mathrm{pH}$-responsive nanocomposite. CNFs and their integration as smart functional material in real world applications offer many advantages. ${ }^{103} \mathrm{CNF}$ reinforcement can enhance the functionality

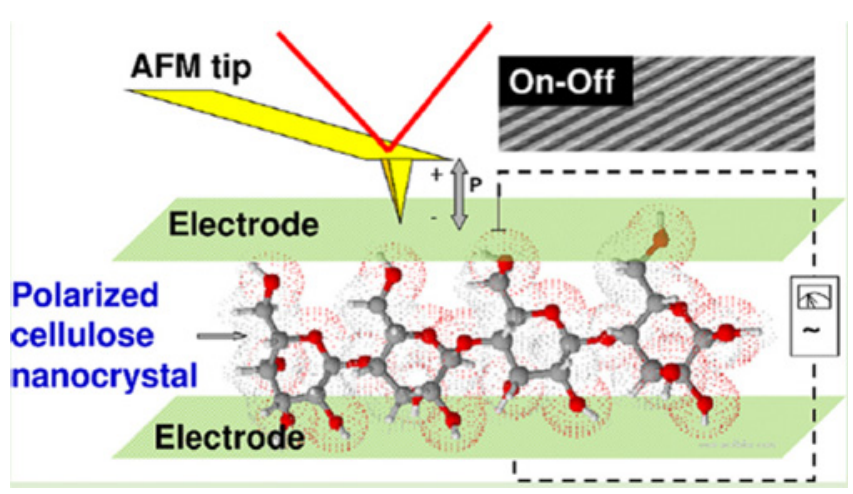

Fig. 15 Schematic of piezoelectric phenomena of cellulose nanocrystals thin films and its image by piezoelectric force microscope ${ }^{97}$ 
of aerogels, and stimuli-responsive materials as compared to conventional materials. ${ }^{104}$ The advantage of using CNF instead of wood based pulp fiber is that the nanofibrils enable the reinforcement of the thin cell walls in matrix. The larger dimensions of wood based fibers make them less suitable for structure reinforcement. The enhanced bond strength between fibers is very attractive for paper making industry and to produce grease-free paper. ${ }^{105}$ The shape memory properties of smart polyurethane were modified by reinforcing Polyaniline (PANi)-coated cellulose nano fibers. ${ }^{106}$ The two-phase structure of the polymer is responsible for the material's ability to remember and autonomously recover its original shape after being deformed in response to an external thermal stimulus. The use of conductive CNFs opens the future possibility of triggering the shape memory response of these cellulose-PU composites through the use of a stimulus other than temperature, although PANi deposition should be optimized for that purpose.

\subsection{Bacterial Cellulose Based Nanocomposites}

$\mathrm{BC}$ has excellent intrinsic properties, and can be used as reinforcement for nanocomposites, actuation systems, and biomedical applications. ${ }^{107}$ The electromechanical performance of $\mathrm{LiCl}$ treated $\mathrm{BC}$ revealed much large bending deformation because of its lower stiffness and higher ionic exchange capacity through the proper control of crystallinity. ${ }^{108}$ In the fully hydrated state the composite shows bending actuation on application of both step and harmonic electrical inputs. The composite exhibits a transient displacement of $0.6 \mathrm{~mm}$ and a steady state displacement of $0.2 \mathrm{~mm}$ under a DC excitation of $2.5 \mathrm{~V}$. The actuator stores an electrical energy of $0.8 \mathrm{~mA} \mathrm{~cm}^{-2}$ at $0.5 \mathrm{~Hz}$ and $3.0 \mathrm{~V}$. BC actuator can be a promising smart material that may possibly be used in the wet environment of diverse biomedical applications. BC pellicles with ferrite particles were found to be superparamagnetic at room temperature. ${ }^{109}$ Magnetic $\mathrm{BC}$ can exhibit variety of magnetic structures, which can be exploited for magnetism based technologies such as magnetic actuator or as a magnetic paper. The $\mathrm{BC}$ impregnated with Ni nanoparticles was found to exhibit both ferromagnetic and

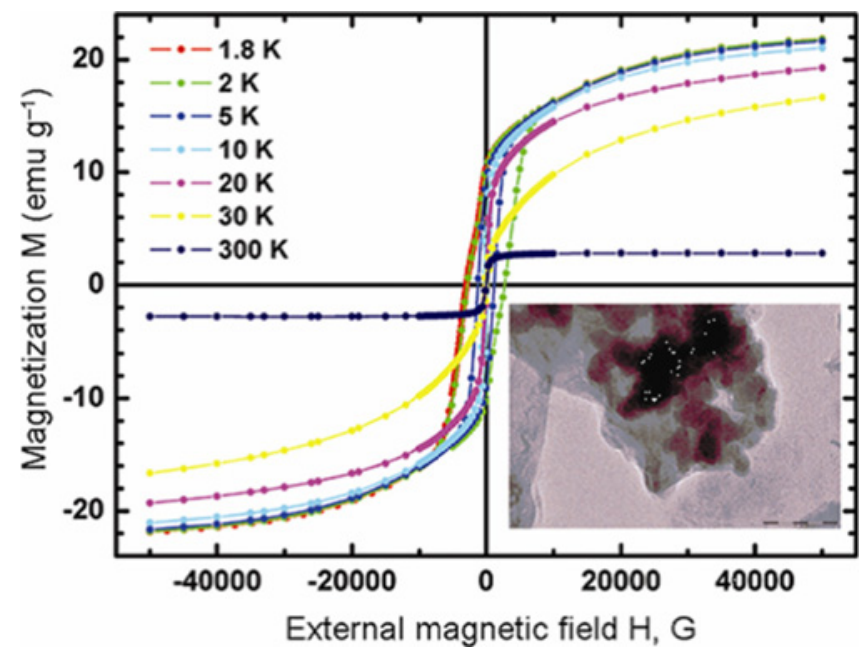

Fig. 16 The ferromagnetic nature of Ni nanoparticles is preserved even when they are impregnated into the $\mathrm{BC}$ matrix, as shown by the hysteresis behavior. Transmission electron microscopy clearly shows the Ni nanoparticles trapped in $\mathrm{BC}^{110}$ superparamagnetic behavior at room temperature with a saturation magnetization of $2.81 \mathrm{emu} \mathrm{g}^{-1}$ which increases by an order of magnitude to $21.8 \mathrm{emu} \mathrm{g}^{-1}$ at $1.8 \mathrm{~K}$ (Fig. 16). ${ }^{110}$ The coercive field also increases by two orders of magnitude from $28 \mathrm{G}$ at $300 \mathrm{~K}$ to $2900 \mathrm{G}$ at $1.8 \mathrm{~K}$. The magnetization decrease with increasing temperature up to $400 \mathrm{~K}$, when extrapolated to high temperatures using a power law indicates a Curie transition at $500 \mathrm{~K}$, much lower than the Curie temperature of bulk $\mathrm{Ni}$.

\section{Energy and Electronic Applications}

Combined with the ability to accommodate other functional materials, cellulose has many opportunities for applications in electrical, electrochemical, and optical devices. Using nano-scaled cellulose fibers, the advanced application has been suggested and studied. During past decade, research on nanostructures of cellulose has increased dramatically due to the potential applications in electronics, biosensors, and energy storage devices. Development of nanostructured inorganic materials in the form of nanocrystals, nanowires, and nanotubes provides a list of functional inks for integration into paper. ${ }^{11}$

\subsection{Cellulose for Energy Storage}

Cellulose is very interesting for an energy storage system due to its structural advantage. Using liquid electrolytes, ionic species can move between the electrode surfaces due to porosity in cellulose at room temperature condition. As an electrode on cellulose, conducting materials such as conductive metal oxide, graphene, carbon nanotubes (CNTs), metal nanowires, and conducting polymers have been suggested and investigated. ${ }^{112}$

As a promising candidate for energy application using $\mathrm{NC}$, the cellulose based flexible energy storage device was made by using cellulose and MWCNT. ${ }^{113}$ The simple structure is based on a single sheet of conductive cellulose paper (separator) made from room temperature ionic liquid and CNT (electrode). The as-fabricated

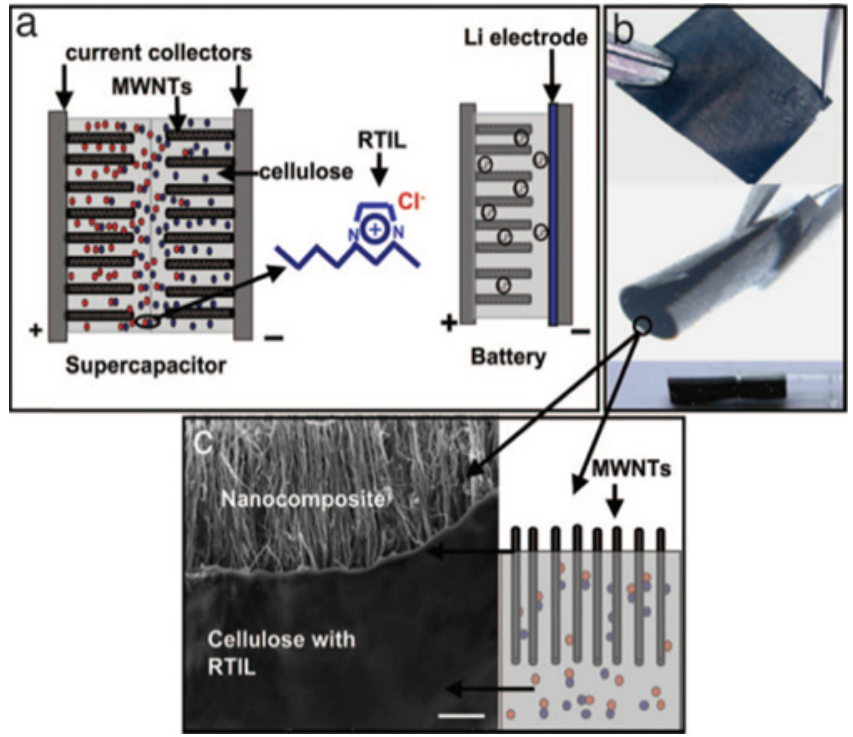

Fig. 17 Cellulose based supercapacitor and battery ${ }^{113}$ 
flexible lithium-ion battery exhibited a specific capacity of $110 \mathrm{mAh} / \mathrm{g}$ by using aqueous $6 \mathrm{M} \mathrm{KOH}$. Fig. 17 shows the schematic of cellulose based flexible energy storage. Cellulose in available nanofibers, nanocrystals and its derivatives also has been suggested for high power Li-ion battery (LIB) application as separators, electrolytes and electrodes. The advantage of cellulose based LIB is the simple integration process which includes a single flexible paper structure where nano-fibrillated cellulose severed both for binding the electrode materials and realizing separator, shown in Fig. 18. ${ }^{114}$

Using microfibrillated cellulose as reinforcement for LIB polymer electrolytes, composite membranes with excellent mechanical properties $\left(\mathrm{E} \sim 80 \mathrm{MPa}\right.$ ), electrical high ionic conductivity (approaching $10^{3} \mathrm{~S} / \mathrm{cm}$ ), and stable overall electrochemical performances was also reported. ${ }^{115}$ Very recently, a nanofibrillated cellulose composite with a liquid electrolyte was reported for a very high elastic modulus around $400 \mathrm{MPa}$ while the values of ionic conductivity is about $5 \times 10^{-5} \mathrm{~S} / \mathrm{cm}$ for LIB application. ${ }^{116}$

As another type of energy storage type, Zhu et al. investigated sodium-ion battery (SIB) using natural wood fiber as electrolyte reservoir. The mesoporous structure of wood fiber as an electrolyte reservoir that allows for ion transport through the outer and inner surface of the fiber. A stable cycling performance with an initial capacity of $339 \mathrm{mAh} / \mathrm{g}$ was successfully demonstrated. The new approach will be utilized for low cost Na-ion based batteries. ${ }^{117}$

For commercialized productions, Enfucell in Finland has developed a disposable, paper-thin and flexible printed power source based on zinc and manganese dioxide for applications like transdermal pharmaceutical and cosmetics patches, wireless medical and logistics sensors, functional packaging. Unfortunately Enfucell is not rechargeable type. Another paper based battery was suggested for ultrathin recyclable flexible paper based battery with longer cell lifetime up to 105 cycles. The sample thickness is less than 400 um. $^{118,119}$

\subsection{Cellulose for Display Device}

As display substrates, flexible, low-CTE and optically transparent wood-cellulose nanocomposites can be another important candidate. Successful organic light emitting diode (OLED) devices was demonstrated. ${ }^{120}$ They achieved the $21 \mathrm{ppm} / \mathrm{K}$ of CTE value from cellulose substrate for OLED display. Recently, transparent and flexible nanocomposite composed of BC and PU based resin was successfully developed as a substrate for OLED with high light transmittance of up to $80 \%$, good stability up to $200 \mathrm{~cd} / \mathrm{m}^{2}$ and dimensional stability in terms of CTE of as low as $18 \mathrm{ppm} / \mathrm{K} .^{121}$

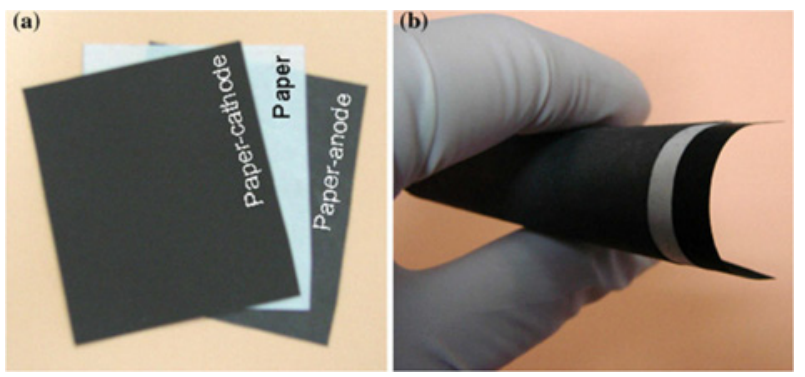

Fig. 18 Images of cellulose battery (a) Made with paper-cathode, separator and paper-anode and (b) Foldable structure ${ }^{114}$

\subsection{Cellulose for Energy Harvester}

$80 \%$ of all photovoltaic solar panels are made with crystalline silicon due to its long-term performance and good reliability. However but most of it occurs in compounds that would be costly to extract the pure silicon. Cellulose can also be used the flexible substrates for solar application. Two major achievements of solar cell on paper were reported. The world first solar panel on paper was developed from research Gr. of MIT. The paper photovoltaic arrays were deposited CVD methods and later printed on normal paper by roll-to-roll process. Another approach was performed from German research group. Using 3PV (printed paper photovoltaic) with conventional printing methods, polymer/fullerene solar cells were printed on paper using a combination of gravure and flexographic printing techniques.

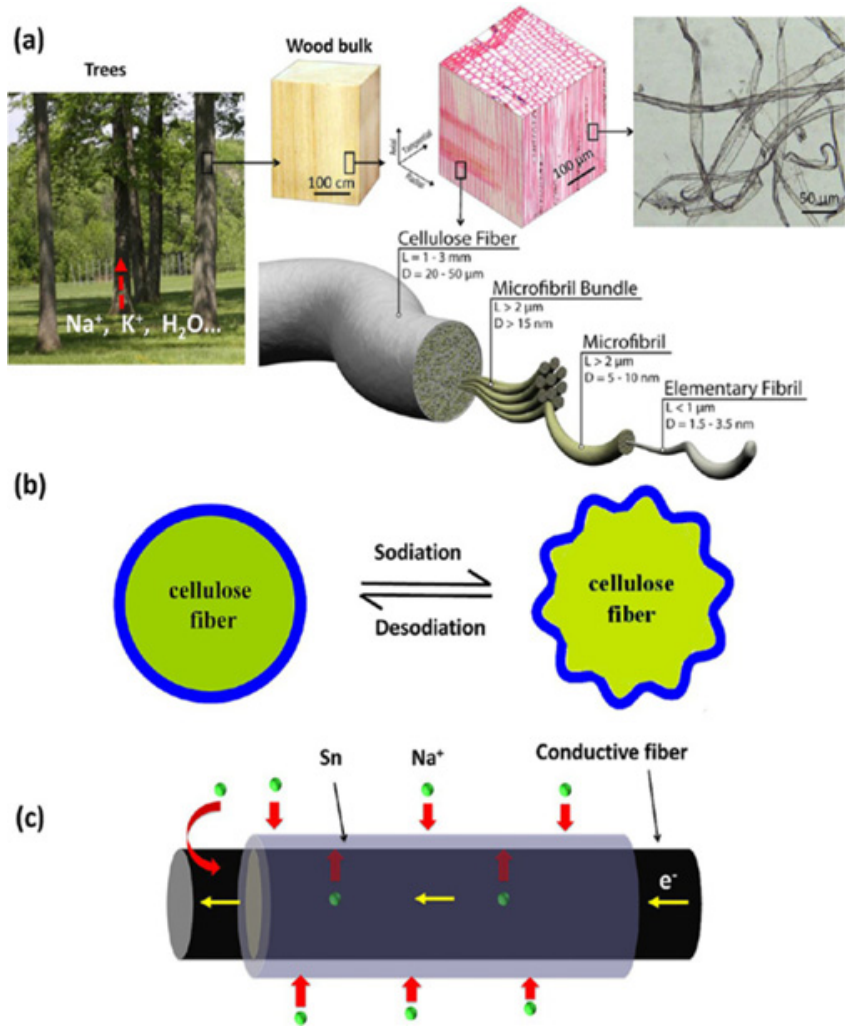

Fig. 19 NC fibril based Sodium ion battery (a) Extraction from wood (b) Sodiation process of cellulose nanofiber and (c) Mechanism of sodium-ion battery (SIB) $)^{117}$

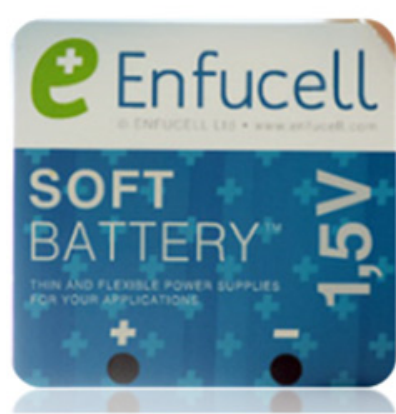

(a)

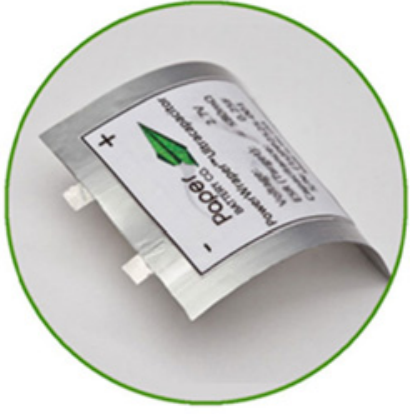

(b)
Fig. 20 The images of paper based battery from (a) Enfucell ${ }^{118}$ and (b) Paperbattery Co. ${ }^{119}$ 


\subsection{Paper Transistor}

As the cheap and nature friendly substrate in semiconductor industry, cellulose also can be considered for potential transparent insulating or semiconducting material. Paper based transistor was reported for low-cost, flexible, and disposable microelectronics, such as biosensors, intelligent packaging, which was considered the prerogative of organic semiconductors to be compatible with paper substrates. ${ }^{111}$ The suggested paper based transistor cannot replace silicon transistors due to scaling down issue, while it can be for some low-cost, disposable applications. By utilizing a printing technique, low-cost flexible paper based electronic device can fulfill the requirements for a fast and low-cost manufacturing process and the use of inexpensive disposable substrates from nature.

Compared to printed electronics, modification of cellulose and appropriate process technique will pave the new way in electronics based on cellulose, called 'papertronics'. Based on these approaches, cellulose can be extended even further electronic applications by modification of cellulose was suggested. By covalently bonding of nanotube in cellulose fibril, a transparent paper transistor as a semiconducting layer was fabricated. ${ }^{111,124,125}$

\section{Conclusions}

The recent achievements of NC from the material extraction and the composite processing to smart materials, electronic and energy applications were reviewed. $\mathrm{NC}$ in the form of nanocrystal or nanofiber, has unique properties including high elastic modulus, dimensional stability, low thermal expansion coefficient, outstanding reinforcing potential and transparency. $\mathrm{NC}$ extraction from natural

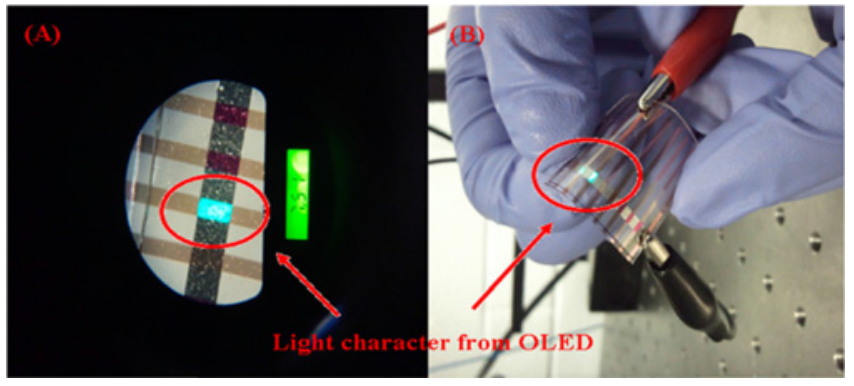

Fig. 21 Luminescence of an organic light-emitting diode deposited onto a flexible, low-CTE and optically transparent wood-cellulose nanocomposite from (a) Ref. 120 and (b) Ref. 121

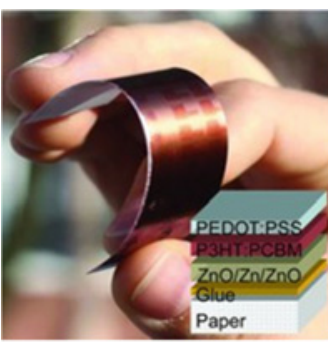

(a)

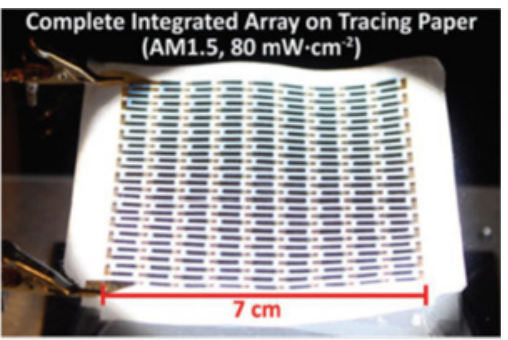

(b)
Fig. 22 (a) Cellulose based flexible organic solar cell ${ }^{122}$ (b) and roll-toroll printed paper solar sheet ${ }^{123}$ resources is the first important step in this research, and there are two methods: chemical and mechanical methods. Chemical methods can break cellulose fiber into nanocrystals or modify the cellulose surface properties although it requires a lot of chemical usage. Mechanical methods of $\mathrm{NC}$ extraction have merits in terms of eco-friendly and chemical free but not suitable for precise material procession. Thus, these two methods need to be compromised for achieving precise and eco-friendly material processing.

The extract NC can be aligned, processed and modified for long fibers, films, powders and suspensions. Because currently available biopolymers are neither satisfactorily offering mechanical rigidity nor barrier sealing properties, composite reforming with $\mathrm{NC}$ fibers is required to use them in wide ranges of engineering plastic and commodity plastic applications. While active researches are still being performed, a few fundamental understanding were revealed on desirable processing parameters as well as structural and property relationship of the NC composites. Particularly, mechanical properties such as stiffness and strength of the composites were sternly varied by the sources and the qualities of reinforcing $\mathrm{NC}$, processing methods and conditions, and surface functional groups of the NC. These environmentally friendly engineering composites can surpass current technological limits of composite materials.

$\mathrm{NC}$ can also be applied to smart materials and structures which can change its shape, morphologies and material properties so as to adapt its environmental change. Smart materials based on NC display intelligent behavior in response to electrical input, light, temperature, $\mathrm{pH}$ and magnetic force to develop sensory-actuation systems. Easy chemical modification of NC can allow inorganic hybrid materials so as to extend its functionality of cellulose, which can be applied to

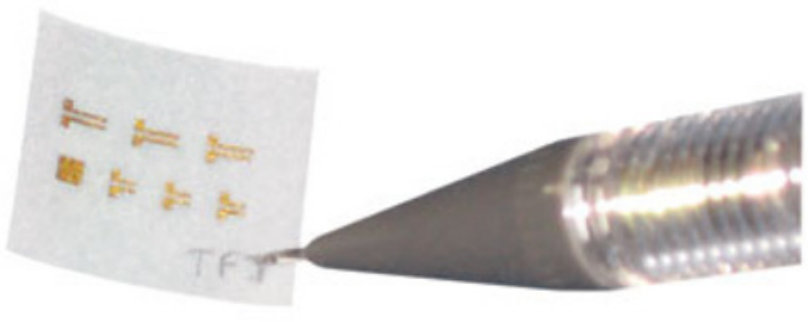

(a)

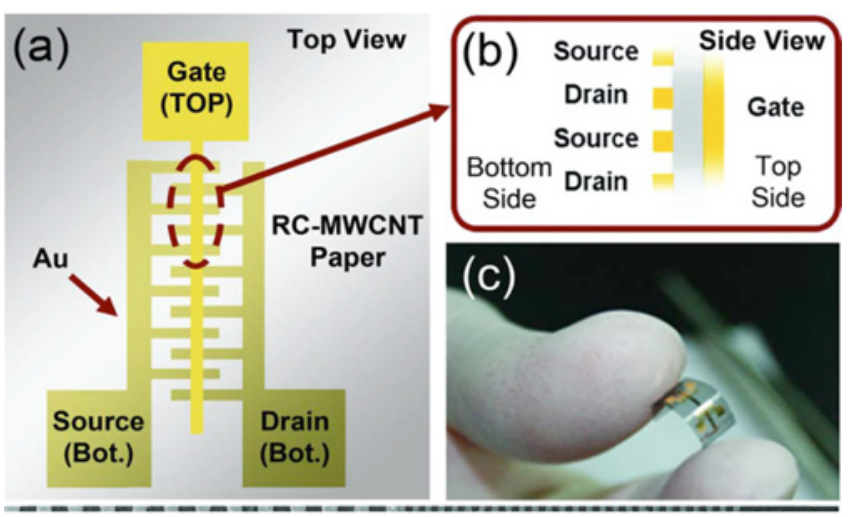

(b)

Fig. 23 Cellulose based paper transistors from (a) Ref. 111 and (b) Ref. 125 
smart devices. NC can be applied to energy devices, for example, paper batteries, supercapacitors and paper displays. Also cellulose applications in electronics are now spreading to wide in the fields from insulating to energy storages, display, semiconducting devices even solar cell applications. Therefore, NC can be an appropriate future sustainable material for wide range applications in our daily life.

Since NC research is booming stage, industrial commercialization is not arrived yet and soon or later it will be reached. There is huge market of NC. It is anticipated that the world market of NC will be 60 billion dollars in 2020. However, another technological breakthrough is urgent in NC research. Once an ultra-strong fiber with lightweight and low price can be made with $\mathrm{NC}$, like carbon fiber, then load-bearing composites can be made, which are essential for future automobiles and wind turbines. This kind of technology breakthrough will trigger the $\mathrm{NC}$ market soaring in the future. Also, regulation and standardization of NC for safety and properties will be necessary for further commercialization.

\section{ACKNOWLEDGEMENT}

This work was supported by National Research Foundation (NRF2013M3C1A3059586) of Korea.

\section{REFERENCES}

1. Gordon, J. E., "The New Science of Strong Materials: Or Why You Don't Fall through the Floor," Penguin, pp. 254-265, 1976

2. Klemm, D., Heublein, B., Fink, H. P., and Bohn, A., "Cellulose: Fascinating Biopolymer and Sustainable Raw Material," Angewandte Chemie International Edition, Vol. 44, No. 22, pp. 3358-3393, 2005.

3. Ball, P., "Material Witness: In Praise of Wood," Nature Materials, Vol. 4, p. 515, 2005.

4. Moon, R. J., Martini, A., Nairn, J., Simonsen, J., and Youngblood, J., "Cellulose Nanomaterials Review: Structure, Properties and Nanocomposites," Chemical Society Reviews, Vol. 40, No. 7, pp. 3941-3994, 2011.

5. Chu, W.-S., Chun, D.-M., and Ahn, S.-H., "Research Advancement of Green Technologies," Int. J. Preci. Eng. Manuf., Vol. 15, No. 6, pp. 973-977, 2014.

6. Hubbe, M. A., Rojas, O. J., Lucia, L. A., and Sain, M., "Cellulosic Nanocomposites: A Review," Bioresources, Vol. 3, No. 3, pp. 929980, 2008.

7. Bhatnagar, A. and Sain, M., "Processing of Cellulose NanofiberReinforced Composites," Journal of Reinforced Plastics and Composites, Vol. 24, No. 12, pp. 1259-1268, 2005.

8. Hon, D. N.-S. and Shiraishi, N., "Wood and Cellulosic Chemistry," Marcel Dekker, New York, $2^{\text {nd }} E d ., 2001$.
9. Bondeson, D., Mathew, A., and Oksman, K., "Optimization of the Isolation of Nanocrystals from Microcrystalline Cellulose by Acid Hydrolysis," Cellulose, Vol. 13, No. 2, pp. 171-180, 2006.

10. Siró, I. and Plackett, D., "Microfibrillated Cellulose and New Nanocomposite Materials: A Review," Cellulose, Vol. 17, No. 3, pp. 459-494, 2010.

11. Habibi, Y., Lucia, L. A., and Rojas, O. J., "Cellulose Nanocrystals: Chemistry, Self-Assembly, and Applications," Chemical Reviews, Vol. 110, No. 6, pp. 3479-3500, 2010.

12. Henriksson, M. and Berglund, L. A., "Structure and Properties of Cellulose Nanocomposite Films Containing Melamine Formaldehyde," Journal of Applied Polymer Science, Vol. 106, No. 4, pp. 2817-2824, 2007.

13. McCormick, C. L., Callais, P. A., and Hutchinson Jr, B. H., "Solution Studies of Cellulose in Lithium Chloride and N, NDimethylacetamide," Macromolecules, Vol. 18, No. 12, pp. 23942401, 1985.

14. Kim, K.-B. and Kim, J., "Fabrication and Characterization of Electro-Active Cellulose Films Regenerated by using 1-Butyl-3Methylimidazolium Chloride Ionic Liquid," Proc. of the Institution of Mechanical Engineers, Part C: Journal of Mechanical Engineering Science, Vol. 227, No. 12, pp. 2665-2670, 2013.

15. Mahadeva, S. K., Kim, J., and Jo, C., "Effect of Hydrophobic Ionic Liquid Loading on Characteristics and Electromechanical Performance of Cellulose,” Int. J. Precis. Eng. Manuf., Vol. 12, No. 1, pp. 47-52, 2011.

16. Kim, C.-W., Kim, D.-S., Kang, S.-Y., Marquez, M., and Joo, Y. L., "Structural Studies of Electrospun Cellulose Nanofibers," Polymer, Vol. 47, No. 14, pp. 5097-5107, 2006.

17. Saito, T., Nishiyama, Y., Putaux, J.-L., Vignon, M., and Isogai, A., "Homogeneous Suspensions of Individualized Microfibrils from Tempo-Catalyzed Oxidation of Native Cellulose," Biomacromolecules, Vol. 7, No. 6, pp. 1687-1691, 2006.

18. Iwamoto, S., Nakagaito, A. N., Yano, H., and Nogi, M., "Optically Transparent Composites Reinforced with Plant Fiber-Based Nanofibers,” Applied Physics A, Vol. 81, No. 6, pp. 1109-1112, 2005.

19. Powerex Corporation, "Microfluidlzer," http://www.powrex.co.jp/ product/model/microfluidizer.html (Accessed 26 March 2015)

20. Kondo, T., Kose, R., Naito, H., and Kasai, W., "Aqueous Counter Collision using Paired Water Jets as a Novel Means of Preparing BioNanofibers," Carbohydrate Polymers, Vol. 112, pp. 284-290, 2014.

21. Kose, R., Mitani, I., Kasai, W., and Kondo, T., ““Nanocellulose” as a Single Nanofiber Prepared from Pellicle Secreted by Gluconacetobacter Xylinus using Aqueous Counter Collision," Biomacromolecules, Vol. 12, No. 3, pp. 716-720, 2011.

22. Kose, R., Kasai, W., and Kondo, T., "Switching Surface Properties of Substrates by Coating with a Cellulose Nanofiber Having a High Adsorbability," SEN-I FAKKAISHI, Vol. 67, No. 7, pp. 163-168, 2011. 
23. Joseph, P. V., Joseph, K., and Thomas, S., "Effect of Processing Variables on the Mechanical Properties of Sisal-Fiber-Reinforced Polypropylene Composites," Composites Science and Technology, Vol. 59, No. 11, pp. 1625-1640, 1999.

24. Bledzki, A. K. and Gassan, J., "Composites Reinforced with Cellulose based Fibres," Progress in Polymer Science, Vol. 24, No. 2, pp. 221-274, 1999.

25. Dufresne, A., Cavaillé, J. Y., and Helbert, W., "Thermoplastic Nanocomposites Filled with Wheat Straw Cellulose Whiskers. Part II: Effect of processing and Modeling," Polymer Composites, Vol. 18, No. 2, pp. 198-210, 1997.

26. Bengtsson, M., Le Baillif, M., and Oksman, K., "Extrusion and Mechanical Properties of Highly Filled Cellulose FibrePolypropylene Composites," Composites Part A: Applied Science and Manufacturing, Vol. 38, No. 8, pp. 1922-1931, 2007.

27. Jonoobi, M., Harun, J., Mathew, A. P., and Oksman, K., "Mechanical Properties of Cellulose Nanofiber (CNF) Reinforced Polylactic Acid (PLA) Prepared by Twin Screw Extrusion," Composites Science and Technology, Vol. 70, No. 12, pp. 17421747, 2010.

28. Jonoobi, M., Mathew, A. P., Abdi, M. M., Makinejad, M. D., and Oksman, K., "A Comparison of Modified and Unmodified Cellulose Nanofiber Reinforced Polylactic Acid (PLA) Prepared by Twin Screw Extrusion," Journal of Polymers and the Environment, Vol. 20, No. 4, pp. 991-997, 2012.

29. Frenot, A., Henriksson, M. W., and Walkenström, P., "Electrospinning of Cellulose-Based Nanofibers," Journal of Applied Polymer Science, Vol. 103, No. 3, pp. 1473-1482, 2007.

30. Rodríguez, K., Gatenholm, P., and Renneckar, S., "Electrospinning Cellulosic Nanofibers for Biomedical Applications: Structure and in Vitro Biocompatibility," Cellulose, Vol. 19, No. 5, pp. 1583-1598, 2012.

31. Awal, A., Sain, M., and Chowdhury, M., "Preparation of Cellulosebased Nano-Composite Fibers by Electrospinning and Understanding the Effect of Processing Parameters," Composites Part B: Engineering, Vol. 42, No. 5, pp. 1220-1225, 2011.

32. Favier, V., Cavaille, J. Y., Canova, G. R., and Shrivastava, S. C., "Mechanical Percolation in Cellulose Whisker Nanocomposites," Polymer Engineering \& Science, Vol. 37, No. 10, pp. 1732-1739, 1997.

33. Rhim, J. W., Mohanty, A. K., Singh, S. P., and Ng, P. K., "Effect of the Processing Methods on the Performance of Polylactide Films: Thermocompression Versus Solvent Casting," Journal of Applied Polymer Science, Vol. 101, No. 6, pp. 3736-3742, 2006.

34. Dufresne, A., "Processing of Polymer Nanocomposites Reinforced with Polysaccharide Nanocrystals," Molecules, Vol. 15, No. 6, pp. 4111-4128, 2010.

35. Zhou, C., Chu, R., Wu, R., and Wu, Q., "Electrospun Polyethylene Oxide/Cellulose Nanocrystal Composite Nanofibrous Mats with Homogeneous and Heterogeneous Microstructures," Biomacromolecules, Vol. 12, No. 7, pp. 2617-2625, 2011.
36. Li, X., Tabil, L. G., and Panigrahi, S., "Chemical Treatments of Natural Fiber for Use in Natural Fiber-Reinforced Composites: A Review," Journal of Polymers and the Environment, Vol. 15, No. 1, pp. 25-33, 2007.

37. Azeredo, H., Mattoso, L. H. C., Avena-Bustillos, R. J., Munford, M. L., Wood, D., et al., "Nanocellulose Reinforced Chitosan Composite Films as Affected by Nanofiller Loading and Plasticizer Content," Journal of Food Science, Vol. 75, No. 1, pp. N1-N7, 2010.

38. Podsiadlo, P., Choi, S.-Y., Shim, B., Lee, J., Cuddihy, M., et al., "Molecularly Engineered Nanocomposites: Layer-by-Layer Assembly of Cellulose Nanocrystals," Biomacromolecules, Vol. 6, No. 6, pp. 2914-2918, 2005.

39. Eichhorn, S. J., Dufresne, A., Aranguren, M., Marcovich, N. E., Capadona, J., et al., "Review: Current International Research into Cellulose Nanofibres and Nanocomposites," Journal of Materials Science, Vol. 45, No. 1, pp. 1-33, 2010.

40. Favier, V., Chanzy, H., and Cavaille, J., "Polymer Nanocomposites Reinforced by Cellulose Whiskers," Macromolecules, Vol. 28, No. 18, pp. 6365-6367, 1995.

41. Souza, S. F., Leao, A. L., Cai, J. H., Wu, C., Sain, M., et al., "Nanocellulose from Curava Fibers and their Nanocomposites," Molecular Crystals and Liquid Crystals, Vol. 522, No. 1, pp. 342352, 2010.

42. Qua, E. H., Hornsby, P. R., Sharma, H. S., Lyons, G., and McCall, R. D., "Preparation and Characterization of Poly (Vinyl Alcohol) Nanocomposites Made from Cellulose Nanofibers," Journal of Applied Polymer Science, Vol. 113, No. 4, pp. 2238-2247, 2009.

43. Cho, M.-J. and Park, B.-D., "Tensile and Thermal Properties of Nanocellulose-Reinforced Poly (Vinyl Alcohol) Nanocomposites," Journal of Industrial and Engineering Chemistry, Vol. 17, No. 1, pp. 36-40, 2011

44. Liu, D., Sun, X., Tian, H., Maiti, S., and Ma, Z., "Effects of Cellulose Nanofibrils on the Structure and Properties on PVA Nanocomposites," Cellulose, Vol. 20, No. 6, pp. 2981-2989, 2013.

45. Pereira, A. L. S., Do, N., D. M., Morais, J. P. S., Vasconcelos, N. F., Feitosa, J. P., et al., "Improvement of Polyvinyl Alcohol Properties by Adding Nanocrystalline Cellulose Isolated from Banana Pseudostems," Carbohydrate Polymers, Vol. 112, pp. 165-172, 2014.

46. Ramezani, K., A., Cheng, S., Sain, M., and Asiri, A., "Mechanical, Thermal, and Morphological Properties of Nanocomposites based on Polyvinyl Alcohol and Cellulose Nanofiber from Aloe Vera Rind," Journal of Nanomaterials, Vol. 2014, Paper No. 903498, 2014.

47. Jalal U., A., Araki, J., and Gotoh, Y., "Toward "Strong" Green Nanocomposites: Polyvinyl Alcohol Reinforced with Extremely Oriented Cellulose Whiskers," Biomacromolecules, Vol. 12, No. 3, pp. 617-624, 2011.

48. Liu, D. Y., Yuan, X. W., Bhattacharyya, D., and Easteal, A. J., "Characterisation of Solution Cast Cellulose Nanofibre-Reinforced Poly (Lactic Acid)," Express Polymer Letters, Vol. 4, No. 1, pp. 26-31, 2010. 
49. Mathew, A. P., Oksman, K., and Sain, M., "Mechanical Properties of Biodegradable Composites from Poly Lactic Acid (PLA) and Microcrystalline Cellulose (MCC)," Journal of Applied Polymer Science, Vol. 97, No. 5, pp. 2014-2025, 2005.

50. Lu, T., Jiang, M., Xu, X., Zhang, S., Hui, D., et al., "The Effects on Mechanical Properties and Crystallization of Poly (L-Lactic Acid) Reinforced by Cellulosic Fibers with Different Scales," Journal of Applied Polymer Science, Vol. 131, No. 22, 2014.

51. Iwatake, A., Nogi, M., and Yano, H., "Cellulose NanofiberReinforced Polylactic Acid," Composites Science and Technology, Vol. 68, No. 9, pp. 2103-2106, 2008.

52. Xu, X., Wang, H., Jiang, L., Wang, X., Payne, S. A., et al., "Comparison between Cellulose Nanocrystal and Cellulose Nanofibril Reinforced Poly(Ethylene Oxide) Nanofibers and their Novel Shish-Kebab-Like Crystalline Structures," Macromolecules, Vol. 47, No. 10, pp. 3409-3416, 2014.

53. Xu, X., Liu, F., Jiang, L., Zhu, J. Y., Haagenson, D., et al., "Cellulose Nanocrystals vs. Cellulose Nanofibrils: A Comparative Study on Their Microstructures and Effects as Polymer Reinforcing Agents," ACS Applied Materials \& Interfaces, Vol. 5, No. 8, pp. 2999-3009, 2013.

54. Khan, A., Khan, R. A., Salmieri, S., Le, T., C., Riedl, B., et al., "Mechanical and Barrier Properties of Nanocrystalline Cellulose Reinforced Chitosan Based Nanocomposite Films," Carbohydrate Polymers, Vol. 90, No. 4, pp. 1601-1608, 2012.

55. Agustin, M. B., Ahmmad, B., Alonzo, S. M. M., and Patriana, F. M., "Bioplastic based on Starch and Cellulose Nanocrystals from Rice Straw," Journal of Reinforced Plastics and Composites, Paper No. $0731684414558325,2014$.

56. Zainuddin, S., Ahmad, I., and Kargarzadeh, H., "Cassava Starch Biocomposites Reinforced with Cellulose Nanocrystals from Kenaf Fibers," Composite Interfaces, Vol. 20, No. 3, pp. 189-199, 2013.

57. Wang, Y., Cao, X., and Zhang, L., "Effects of Cellulose Whiskers on Properties of Soy Protein Thermoplastics," Macromolecular Bioscience, Vol. 6, No. 7, pp. 524-531, 2006.

58. Huang, X. and Netravali, A., "Biodegradable Green Composites Made using Bamboo Micro/Nano-Fibrils and Chemically Modified Soy Protein Resin," Composites Science and Technology, Vol. 69, No. 7, pp. 1009-1015, 2009.

59. Jensen, A., Lim, L.-T., Barbut, S., and Marcone, M., "Development and Characterization of Soy Protein Films Incorporated with Cellulose Fibers using a Hot Surface Casting Technique," LWTFood Science and Technology, Vol. 60, No. 1, pp. 162-170, 2015.

60. Siró, I. and Plackett, D., "Microfibrillated Cellulose and New Nanocomposite Materials: A Review," Cellulose, Vol. 17, No. 3, pp. 459-494, 2010.

61. Syverud, K. and Stenius, P., "Strength and Barrier Properties of MFC Films," Cellulose, Vol. 16, No. 1, pp. 75-85, 2009.
62. Sanchez-Garcia, M. D. and Lagaron, J. M., "On the Use of Plant Cellulose Nanowhiskers to Enhance the Barrier Properties of Polylactic Acid,” Cellulose, Vol. 17, No. 5, pp. 987-1004, 2010.

63. Fukuya, M. N., Senoo, K., Kotera, M., Yoshimoto, M., and Sakata, O., "Enhanced Oxygen Barrier Property of Poly (Ethylene Oxide) Films Crystallite-Oriented by Adding Cellulose Single Nanofibers," Polymer, Vol. 55, No. 22, pp. 5843-5846, 2014.

64. Gil, E. S. and Hudson, S. M., "Stimuli-Reponsive Polymers and Their Bioconjugates," Progress in Polymer Science, Vol. 29, No. 12, pp. 1173-1222, 2004.

65. Kim, J., Yun, S., and Ounaies, Z., "Discovery of Cellulose as a Smart Material,” Macromolecules, Vol. 39, No. 12, pp. 4202-4206, 2006.

66. Peng, J., Liu, Q., Xu, Z., and Masliyah, J., "Synthesis of Interfacially Active and Magnetically Responsive Nanoparticles for Multiphase Separation Applications," Advanced Functional Materials, Vol. 22, No. 8, pp. 1732-1740, 2012.

67. Qiu, X. and Hu, S., “"Smart” Materials based on Cellulose: A Review of the Preparations, Properties, and Applications," Materials, Vol. 6, No. 3, pp. 738-781, 2013.

68. Prabaharan, M. and Mano, J. F., "Stimuli-Responsive Hydrogels based on Polysaccharides Incorporated with Thermo-Responsive Polymers as Novel Biomaterials," Macromolecular Bioscience, Vol. 6, No. 12, pp. 991-1008, 2006.

69. Zhang, Z., Chen, L., Zhao, C., Bai, Y., Deng, M., et al., "Thermoand pH-Responsive HPC-g-AA/AA Hydrogels for Controlled Drug Delivery Applications," Polymer, Vol. 52, No. 3, pp. 676-682, 2011.

70. Peresin, M. S., Zoppe, J. O., Vallejos, M. E., Habibi, Y., Hubbe, M. A., et al., "Nano-and Micro-Fiber Composites Reinforced with Cellulose Nanocrystals," Cellulose based Composites: New Green Nanomaterials, Wiley-VCH Verlag GmbH, 2014.

71. Kettunen, M., Silvennoinen, R. J., Houbenov, N., Nykänen, A., Ruokolainen, J., et al., "Photoswitchable Superabsorbency based on Nanocellulose Aerogels," Advanced Functional Materials, Vol. 21, No. 3, pp. 510-517, 2011.

72. Kim, J., Lee, H., Kim, H. S., and Kim, J., "Vibration Sensor Characteristics of Piezoelectric Electro-Active Paper," Journal of Intelligent Material Systems and Structures, Vol. 21, No. 11, pp. 1123-1130, 2010.

73. Abas, Z., Kim, H. S., Zhai, L., Kim, J., and Kim, J. H., "Possibility of Cellulose-Based Electro-Active Paper Energy Scavenging Transducer," Journal of Nanoscience and Nanotechnology, Vol. 14, No. 10, pp. 7458-7462, 2014.

74. Kim, J., Yun, S., Mahadeva, S. K., Yun, K., Yang, S. Y., et al., "Paper Actuators Made with Cellulose and Hybrid Materials," Sensors, Vol. 10, No. 3, pp. 1473-1485, 2010.

75. Yun, G.-Y., Kim, J., Kim, J.-H., and Kim, S.-Y., "Fabrication and Testing of Cellulose Eapap Actuators for Haptic Application," Sensors and Actuators A: Physical, Vol. 164, No. 1, pp. 68-73, 2010. 
76. Yang, S. Y., Mahadeva, S. K., and Kim, J., "Wirelessly Driven Electro-Active Paper Actuator Made with Cellulose-PolypyrroleIonic Liquid and Dipole Rectenna," Smart Materials and Structures, Vol. 19, No. 10, Paper No. 105026, 2010.

77. Yang, S. Y., Mahadeva, S. K., and Kim, J., "Remotely Powered and Controlled Eapap Actuator by Amplitude Modulated Microwaves," Smart Materials and Structures, Vol. 22, No. 1, Paper No. 017001, 2013.

78. Yun, S. and Kim, J., "A Bending Electro-Active Paper Actuator Made by Mixing Multi-Walled Carbon Nanotubes and Cellulose," Smart Materials and Structures, Vol. 16, No. 4, pp. 1471-1476, 2007.

79. Yun, S. and Kim, J., "Characteristics and Performance of Functionalized MWNT Blended Cellulose Electro-Active Paper Actuator," Synthetic Metals, Vol. 158, No. 13, pp. 521-526, 2008.

80. Cai, Z. and Kim, J., "Characterization and Electromechanical Performance of Cellulose-Chitosan Blend Electro-Active Paper," Smart Materials and Structures, Vol. 17, No. 3, Paper No. 035028, 2008.

81. Orts, W. J., Shey, J., Imam, S. H., Glenn, G. M., Guttman, M. E., et al., "Application of Cellulose Microfibrils in Polymer Nanocomposites," Journal of Polymers and the Environment, Vol. 13, No. 4, pp. 301-306, 2005.

82. Wu, Q., Henriksson, M., Liu, X., and Berglund, L. A., "A High Strength Nanocomposite based on Microcrystalline Cellulose and Polyurethane,” Biomacromolecules, Vol. 8, No. 12, pp. 3687-3692, 2007.

83. Marques, P. A., Trindade, T., and Neto, C. P., "Titanium Dioxide/ Cellulose Nanocomposites Prepared by a Controlled Hydrolysis Method," Composites Science and Technology, Vol. 66, No. 7, pp. 1038-1044, 2006.

84. Zhou, J., Li, R., Liu, S., Li, Q., Zhang, L., et al., "Structure and Magnetic Properties of Regenerated Cellulose/Fe3o4 Nanocomposite Films," Journal of Applied Polymer Science, Vol. 111, No. 5, pp. 2477-2484, 2009.

85. Mahadeva, S. K., Nayak, J., and Kim, J., "Hybrid Composite Thin Films Composed of Tin Oxide Nanoparticles and Cellulose," Smart Materials and Structures, Vol. 22, No. 7, Paper No. 075011, 2013.

86. Kang, B.-W., Mun, S., Ko, H.-U., Zhai, L., Kim, J.-H., et al., "Electromechanical Behavior of Green Cellulose-ZnO Hybrid Nanocomposite," Journal of Biobased Materials and Bioenergy, Vol. 8, No. 2, pp. 137-142, 2014.

87. Ren, X., Chen, D., Meng, X., Tang, F., Du, A., et al., "Amperometric Glucose Biosensor based on a Gold Nanorods/ Cellulose Acetate Composite Film as Immobilization Matrix," Colloids and Surfaces B: Biointerfaces, Vol. 72, No. 2, pp. 188-192, 2009.

88. Mahadeva, S. K. and Kim, J., "Conductometric Glucose Biosensor Made with Cellulose and Tin Oxide Hybrid Nanocomposite," Sensors and Actuators B: Chemical, Vol. 157, No. 1, pp. 177-182, 2011.
89. Yun, S. and Kim, J., "Multi-Walled Carbon Nanotubes-Cellulose Paper for a Chemical Vapor Sensor," Sensors and Actuators B: Chemical, Vol. 150, No. 1, pp. 308-313, 2010.

90. Karthigeyan, A., Minami, N., and Iakoubovskii, K., "Highly Sensitive, Room-Temperature Gas Sensors Prepared from Cellulose Derivative Assisted Dispersions of Single-Wall Carbon Nanotubes," Japanese Journal of Applied Physics, Vol. 47, No. 9, pp. 7440-7443, 2008.

91. Han, J.-W., Kim, B., Li, J., and Meyyappan, M., "A Carbon Nanotube based Ammonia Sensor on Cellulose Paper," RSC Advances, Vol. 4, No. 2, pp. 549-553, 2014.

92. Ducéré, V., Bernès, A., and Lacabanne, C., "A Capacitive Humidity Sensor using Cross-Linked Cellulose Acetate Butyrate," Sensors and Actuators B: Chemical, Vol. 106, No. 1, pp. 331-334, 2005.

93. Kim, J., Yun, G.-Y., Kim, J.-H., Lee, J., and Kim, J.-H., "Piezoelectric Electro-Active Paper (EaPap) Speaker," Journal of Mechanical Science and Technology, Vol. 25, No. 11, pp. 27632768, 2011.

94. Lee, S.-Y., Mohan, D. J., Kang, I.-A., Doh, G.-H., Lee, S., et al., "Nanocellulose Reinforced PVA Composite Films: Effects of Acid Treatment and Filler Loading," Fibers and Polymers, Vol. 10, No. 1, pp. 77-82, 2009.

95. Gaspar, D., Fernandes, S. N., De Oliveira, A. G., Fernandes, J. G., Grey, P., et al., "Nanocrystalline Cellulose Applied Simultaneously as the Gate Dielectric and the Substrate in Flexible Field Effect Transistors," Nanotechnology, Vol. 25, No. 9, Paper No. 094008, 2014.

96. Shi, Z., Phillips, G. O., and Yang, G., "Nanocellulose Electroconductive Composites," Nanoscale, Vol. 5, No. 8, pp. 31943201, 2013.

97. Csoka, L., Hoeger, I. C., Rojas, O. J., Peszlen, I., Pawlak, J. J., et al., "Piezoelectric Effect of Cellulose Nanocrystals Thin Films," ACS Macro Letters, Vol. 1, No. 7, pp. 867-870, 2012.

98. Auad, M. L., Contos, V. S., Nutt, S., Aranguren, M. I., and Marcovich, N. E., "Characterization of Nanocellulose-Reinforced Shape Memory Polyurethanes," Polymer International, Vol. 57, No. 4, pp. 651-659, 2008.

99. Capadona, J. R., Shanmuganathan, K., Tyler, D. J., Rowan, S. J., and Weder, C., "Stimuli-Responsive Polymer Nanocomposites Inspired by the Sea Cucumber Dermis," Science, Vol. 319, No. 5868, pp. 1370-1374, 2008.

100. Shanmuganathan, K., Capadona, J. R., Rowan, S. J., and Weder, C., "Stimuli-Responsive Mechanically Adaptive Polymer Nanocomposites," ACS Applied Materials \& Interfaces, Vol. 2, No. 1, pp. 165-174, 2009.

101. Shanmuganathan, K., Capadona, J. R., Rowan, S. J., and Weder, C., "Bio-Inspired Mechanically-Adaptive Nanocomposites Derived from Cotton Cellulose Whiskers," Journal of Materials Chemistry, Vol. 20, No. 1, pp. 180-186, 2010. 
102. Way, A. E., Hsu, L., Shanmuganathan, K., Weder, C., and Rowan, S. J., "Ph-Responsive Cellulose Nanocrystal Gels and Nanocomposites," ACS Macro Letters, Vol. 1, No. 8, pp. 1001-1006, 2012.

103. Siró, I. and Plackett, D., "Microfibrillated Cellulose and New Nanocomposite Materials: A Review," Cellulose, Vol. 17, No. 3, pp. 459-494, 2010.

104. Tingaut, P., Zimmermann, T., and Sèbe, G., "Cellulose Nanocrystals and Microfibrillated Cellulose as Building Blocks for the Design of Hierarchical Functional Materials," Journal of Materials Chemistry, Vol. 22, No. 38, pp. 20105-20111, 2012.

105. Nakagaito, A. N. and Yano, H., "Toughness Enhancement of Cellulose Nanocomposites by Alkali Treatment of the Reinforcing Cellulose Nanofibers," Cellulose, Vol. 15, No. 2, pp. 323-331, 2008.

106. Auad, M. L., Richardson, T., Orts, W. J., Medeiros, E. S., Mattoso, L. H., et al., "Polyaniline-Modified Cellulose Nanofibrils as Reinforcement of a Smart Polyurethane," Polymer International, Vol. 60, No. 5, pp. 743-750, 2011.

107. Nogi, M., Ifuku, S., Abe, K., Handa, K., Nakagaito, A. N., et al., "Fiber-Content Dependency of the Optical Transparency and Thermal Expansion of Bacterial Nanofiber Reinforced Composites," Applied Physics Letters, Vol. 88, No. 13, Paper No. 133124, 2006.

108. Jeon, J.-H., Oh, I.-K., Kee, C.-D., and Kim, S.-J., "Bacterial Cellulose Actuator with Electrically Driven Bending Deformation in Hydrated Condition," Sensors and Actuators B: Chemical, Vol. 146, No. 1, pp. 307-313, 2010.

109. Sourty, E., Ryan, D. H., and Marchessault, R. H., "Characterization of Magnetic Membranes based on Bacterial and Man-Made Cellulose," Cellulose, Vol. 5, No. 1, pp. 5-17, 1998.

110. Vitta, S., Drillon, M., and Derory, A., "Magnetically Responsive Bacterial Cellulose: Synthesis and Magnetic Studies," Journal of Applied Physics, Vol. 108, No. 5, Paper No. 053905, 2010.

111. Tobjörk, D. and Österbacka, R., "Paper Electronics," Advanced Materials, Vol. 23, No. 17, pp. 1935-1961, 2011.

112. Zheng, G., Cui, Y., Karabulut, E., Wågberg, L., Zhu, H., et al., "Nanostructured Paper for Flexible Energy and Electronic Devices," MRS Bulletin, Vol. 38, No. 4, pp. 320-325, 2013.

113. Pushparaj, V. L., Shaijumon, M. M., Kumar, A., Murugesan, S., Ci, L., et al., "Flexible Energy Storage Devices based on Nanocomposite Paper," Proc. of the National Academy of Sciences, Vol. 104, No. 34, pp. 13574-13577, 2007.

114. Jabbour, L., Bongiovanni, R., Chaussy, D., Gerbaldi, C., and Beneventi, D., "Cellulose-Based Li-Ion Batteries: A Review," Cellulose, Vol. 20, No. 4, pp. 1523-1545, 2013.

115. Chiappone, A., Nair, J. R., Gerbaldi, C., Jabbour, L., Bongiovanni, R., et al., "Microfibrillated Cellulose as Reinforcement for Li-Ion Battery Polymer Electrolytes with Excellent Mechanical Stability," Journal of Power Sources, Vol. 196, No. 23, pp. 10280-10288, 2011.
116. Willgert, M., Leijonmarck, S., Lindbergh, G., Malmström, E., and Johansson, M., "Cellulose Nanofibril Reinforced Composite Electrolytes for Lithium Ion Battery Applications," Journal of Materials Chemistry A, Vol. 2, No. 33, pp. 13556-13564, 2014.

117. Zhu, H., Jia, Z., Chen, Y., Weadock, N., Wan, J., et al., "Tin Anode for Sodium-Ion Batteries using Natural Wood Fiber as a Mechanical Buffer and Electrolyte Reservoir," Nano Letters, Vol. 13, No. 7, pp. 3093-3100, 2013.

118. Enfucell Oy, "SoftBattery", www.enfucell.com/softbattery (Accessed 25 March 2015)

119. Paper Battery Company, "PowerWrapper”, www.paperbatteryco.com /products/powerwrapper (Accessed 25 March 2015)

120. Okahisa, Y., Yoshida, A., Miyaguchi, S., and Yano, H., "Optically Transparent Wood-Cellulose Nanocomposite as a Base Substrate for Flexible Organic Light-Emitting Diode Displays," Composites Science and Technology, Vol. 69, No. 11, pp. 1958-1961, 2009.

121. Ummartyotin, S., Juntaro, J., Sain, M., and Manuspiya, H., "Development of Transparent Bacterial Cellulose Nanocomposite Film as Substrate for Flexible Organic Light Emitting Diode (OLED) Display," Industrial Crops and Products, Vol. 35, No. 1, pp. 92-97, 2012.

122. Hübler, A., Trnovec, B., Zillger, T., Ali, M., Wetzold, N., et al., "Printed Paper Photovoltaic Cells," Advanced Energy Materials, Vol. 1, No. 6, pp. 1018-1022, 2011.

123. Barr, M. C., Rowehl, J. A., Lunt, R. R., Xu, J., Wang, A., et al., "Direct Monolithic Integration of Organic Photovoltaic Circuits on Unmodified Paper," Advanced Materials, Vol. 23, No. 31, pp. 3500-3505, 2011.

124. Fortunato, E., Correia, N., Barquinha, P., Pereira, L., Gonçalves, G., et al., "High-Performance Flexible Hybrid Field-Effect Transistors based on Cellulose Fiber Paper," IEEE Electron Device Letters, Vol. 29, No. 9, pp. 988-990, 2008.

125. Kim, J.-H., Yun, S., Ko, H.-U., and Kim, J., “A Flexible Paper Transistor Made with Aligned Single-Walled Carbon Nanotube Bonded Cellulose Composite," Current Applied Physics, Vol. 13, No. 5, pp. 897-901, 2013. 